\title{
Mesospheric $\mathrm{N}_{2} \mathrm{O}$ enhancements as observed by MIPAS on Envisat during the polar winters in 2002-2004
}

\author{
B. Funke ${ }^{1}$, M. López-Puertas ${ }^{1}$, M. García-Comas ${ }^{1}$, G. P. Stiller ${ }^{2}$, T. von Clarmann ${ }^{2}$, and N. Glatthor ${ }^{2}$ \\ ${ }^{1}$ Instituto de Astrofísica de Andalucía, CSIC, Granada, Spain \\ ${ }^{2}$ Forschungszentrum and University of Karlsruhe, Institut für Meteorologie und Klimaforschung (IMK), Karlsruhe, Germany
}

Received: 12 March 2008 - Published in Atmos. Chem. Phys. Discuss.: 3 June 2008

Revised: 21 August 2008 - Accepted: 26 August 2008 - Published: 7 October 2008

\begin{abstract}
N}_{2} \mathrm{O}$ abundances ranging from 0.5 to $6 \mathrm{ppbv}$ were observed in the polar upper stratosphere/lower mesosphere by the MIPAS instrument on the Envisat satellite during the Arctic and Antarctic winters in the period July 2002 to March 2004. A detailed study of the observed $\mathrm{N}_{2} \mathrm{O}-\mathrm{CH}_{4}$ correlations shows that such enhancements cannot be explained by dynamics without invoking an upper atmospheric chemical source of $\mathrm{N}_{2} \mathrm{O}$. The $\mathrm{N}_{2} \mathrm{O}$ enhancements observed at $58 \mathrm{~km}$ occurred in the presence of $\mathrm{NO}_{\mathrm{x}}$ intrusions from the upper atmosphere which were related to energetic particle precipitation. Further, the inter-annual variability of mesospheric $\mathrm{N}_{2} \mathrm{O}$ correlates well with observed precipitating electron fluxes. The analysis of possible chemical production mechanisms shows that the major part of the observed $\mathrm{N}_{2} \mathrm{O}$ enhancements is most likely generated under dark conditions by the reaction of $\mathrm{NO}_{2}$ with atomic nitrogen at altitudes around $70-75 \mathrm{~km}$ in the presence of energetic particle precipitation (EPP). A possible additional source of $\mathrm{N}_{2} \mathrm{O}$ in the middle and upper polar atmosphere is the reaction of $\mathrm{N}_{2}\left(\mathrm{~A}^{3} \Sigma_{u}^{+}\right)$, generated by precipitating electrons, with $\mathrm{O}_{2}$, which would lead to $\mathrm{N}_{2} \mathrm{O}$ production peaking at altitudes around $90-100 \mathrm{~km} . \mathrm{N}_{2} \mathrm{O}$ produced by the latter mechanism could then descend to the mesosphere and upper stratosphere during polar winter. The estimated fraction of EPPgenerated $\mathrm{N}_{2} \mathrm{O}$ to the total stratospheric $\mathrm{N}_{2} \mathrm{O}$ inside the polar vortex above $20 \mathrm{~km}(30 \mathrm{~km})$ never exceeds $1 \%$ (10\%) during the 2002-2004 winters. Compared to the global amount of stratospheric $\mathrm{N}_{2} \mathrm{O}$, the EPP-generated contribution is negligible.
\end{abstract}

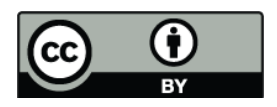

Correspondence to: B. Funke (bernd@iaa.es)

\section{Introduction}

Nitrous oxide is the main precursor of odd nitrogen in the middle atmosphere. Its major sources, both natural and manmade, are located at the surface from where it is transported into the stratosphere. Photolysis by solar UV is its major sink and the reaction with $\mathrm{O}\left({ }^{1} \mathrm{D}\right)$ leads to the formation of NO.

Due to its long chemical lifetime and the apparent absence of sources in the middle atmosphere, $\mathrm{N}_{2} \mathrm{O}$ is an excellent tracer for stratospheric transport processes. In particular, correlations of observed $\mathrm{N}_{2} \mathrm{O}$ abundances with other tracers such as $\mathrm{CH}_{4}$ or CFCs have been widely used in transport studies (Michelsen et al., 1998a; Plumb et al., 2000; Ray et al., 2002).

Recently, however, Funke et al. (2008) reported polar stratospheric and mesospheric $\mathrm{N}_{2} \mathrm{O}$ enhancements in the Northern Hemisphere (NH) in the aftermath of the large solar proton event (SPE) which took place in October-November 2003. These $\mathrm{N}_{2} \mathrm{O}$ enhancements were attributed to chemical production of $\mathrm{N}_{2} \mathrm{O}$ by

$\mathrm{NO}_{2}+\mathrm{N}\left({ }^{4} \mathrm{~S}\right) \rightarrow \mathrm{N}_{2} \mathrm{O}+\mathrm{O}$.

Both species $\left(\mathrm{NO}_{2}\right.$ and $\left.\mathrm{N}\left({ }^{4} \mathrm{~S}\right)\right)$ were largely enhanced as a consequence of ionization caused by solar protons. Semeniuk et al. (2008) reported polar mesospheric $\mathrm{N}_{2} \mathrm{O}$ enhancements in the NH observed by the Fourier Transform Spectrometer on SCISAT-1 during February-April 2004 which were also attributed to the reaction of $\mathrm{NO}_{2}$ and atomic nitrogen. Since no major SPE occurred in this period, these authors assumed that enhanced $\mathrm{N}$ abundances, required for the formation of $\mathrm{N}_{2} \mathrm{O}$, were generated by ionization caused by auroral electron precipitation.

An alternative production mechanism of middle and upper atmospheric $\mathrm{N}_{2} \mathrm{O}$ was proposed by Zipf and Prasad (1980): i.e., metastable $\mathrm{N}_{2}\left(\mathrm{~A}^{3} \Sigma_{u}^{+}\right)$is produced by electron impact during auroral substorms and reacts with $\mathrm{O}_{2}$ to form $\mathrm{N}_{2} \mathrm{O}$ :

$\mathrm{N}_{2}\left(\mathrm{~A}^{3} \Sigma_{u}^{+}\right)+\mathrm{O}_{2} \rightarrow \mathrm{N}_{2} \mathrm{O}+\mathrm{O}$. 
In accordance with laboratory measurements (Zipf, 1980), these authors considered an efficiency of 0.6 to form $\mathrm{N}_{2} \mathrm{O}$ by the reaction of $\mathrm{N}_{2}\left(\mathrm{~A}^{3} \Sigma_{u}^{+}\right)$with molecular oxygen, which would then result in production of enormous amounts of $\mathrm{N}_{2} \mathrm{O}$ around $90-100 \mathrm{~km}$ during geomagnetic perturbations. However, the observation of such a high efficiency for producing $\mathrm{N}_{2} \mathrm{O}$ by Reaction (R2), initially reported by Zipf (1980), has not been confirmed by other groups, and the branching ratio for this channel is probably less than 0.02 (de Sousa et al., 1985; Iannuzzi et al., 1982).

Here, we report upper stratospheric and mesospheric $\mathrm{N}_{2} \mathrm{O}$ enhancements observed by the Michelson Interferometer for Passive Atmospheric Sounding (MIPAS) instrument on Envisat in polar winters during 2002-2004. In Sect. 2, we present the observed spatial distributions of polar winter $\mathrm{N}_{2} \mathrm{O}$ and their temporal evolution. The chemical origin of these $\mathrm{N}_{2} \mathrm{O}$ enhancements is demonstrated in Sect. 3 by means of an analysis of $\mathrm{N}_{2} \mathrm{O}-\mathrm{CH}_{4}$ tracer-tracer correlations, and possible production mechanisms are discussed in Sect. 4.

\section{MIPAS observations and data analysis}

MIPAS is a limb emission Fourier transform spectrometer designed for the measurement of trace species from space (Fischer and Oelhaf, 1996; European Space Agency, 2000; Fischer et al., 2008). It is part of the instrumentation of the Environmental Satellite (ENVISAT) which was launched into its sun-synchronous polar orbit of $98.55^{\circ} \mathrm{N}$ inclination at about $800 \mathrm{~km}$ altitude on 1 March 2002. ENVISAT passes the equator in southerly direction at 10.00 a.m. local time 14.3 times a day. MIPAS operated from July 2002 to March 2004 at full spectral resolution of $0.035 \mathrm{~cm}^{-1}$ (unapodized) in terms of full width at half maximum and has resumed operation with reduced resolution, after an instrument failure, since August 2004. MIPAS observes the atmosphere during day and night with global coverage from pole to pole. Within its standard observation mode at full spectral resolution, MIPAS covers the altitude range from nominally $68 \mathrm{~km}$ down to $6 \mathrm{~km}$ with tangent altitudes at $68,60,52,47$, and then at $3 \mathrm{~km}$ steps from 42 to $6 \mathrm{~km}$. Occasionally, MIPAS also operates in several upper atmospheric measurement modes scanning up to $170 \mathrm{~km}$. The field of view of MIPAS is $30 \mathrm{~km}$ in the horizontal and approximately $3 \mathrm{~km}$ in the vertical. During each orbit up to 72 limb scans are recorded. The Level- 1 b processing of the data (version 4.61/62 was used here), including processing from raw data to calibrated phase-corrected and geolocated radiance spectra, is performed by the European Space Agency (ESA) (Nett et al., 1999, 2002).

\subsection{Analysis of IMK/IAA-generated $\mathrm{N}_{2} \mathrm{O}$ data}

Data presented and discussed in this section are vertical profiles of abundances of $\mathrm{N}_{2} \mathrm{O}$ and $\mathrm{CH}_{4}$ retrieved with the scientific IMK-IAA data processor (von Clarmann et al., 2003a) developed and operated by the Institute of Meteorology and Climate Research (IMK) in Karlsruhe together with the Instituto de Astrofísica de Andalucía (IAA) in Granada. This data processor is based on a constrained non-linear least squares algorithm with Levenberg-Marquardt damping and line by line radiative transfer calculations with the Karlsruhe Optimized and Precise Radiative Transfer Algorithm (KOPRA) (Stiller et al., 2002). The first step in the L 2 processing is the determination of the spectral shift, followed by the retrieval of temperature and elevation pointing (von Clarmann et al., 2003b), where pressure is implicitly determined by means of hydrostatic equilibrium. The retrieval of volume mixing ratio (vmr) profiles of species is carried out in the following order: $\mathrm{O}_{3}, \mathrm{H}_{2} \mathrm{O}, \mathrm{HNO}_{3}$, and then $\mathrm{CH}_{4}$ and $\mathrm{N}_{2} \mathrm{O}$ simultaneously. The results of the species firstly retrieved are used in the retrievals of the subsequent species. The $\mathrm{N}_{2} \mathrm{O} \mathrm{vmr}$ is retrieved from the MIPAS spectra around $1284.9 \mathrm{~cm}^{-1}$, where the $\mathrm{v}_{1}$ band of $\mathrm{N}_{2} \mathrm{O}$ is located (Glatthor et al., 2005). The retrievals are performed from selected spectral regions (micro-windows) which vary with tangent altitudes in order to optimize computation time and minimize systematic errors (Echle et al., 2000). Thus, height dependent combinations of micro-windows were selected with a trade-off between computation time and total retrieval error. The retrieval noise error in the $\mathrm{N}_{2} \mathrm{O} \mathrm{vmr}$ is typically $3 \%$ at $10-44 \mathrm{~km}$ and $22 \%$ at $50 \mathrm{~km}$. The total error varies between 10 and $20 \%$ at 10 $35 \mathrm{~km}$ and is about $30 \%$ between $35-50 \mathrm{~km}$ (Glatthor et al., 2005). The resulting vertical resolution was about $4 \mathrm{~km}$ in the altitude range $15-40 \mathrm{~km}$ and decreased to more than $10 \mathrm{~km}$ below and above this region. More details on the $\mathrm{N}_{2} \mathrm{O}$ retrieval strategy can be found in Glatthor et al. (2005).

Two data sets with different retrieval versions are used in this study: The first one includes $\mathrm{N}_{2} \mathrm{O}$ and $\mathrm{CH}_{4}$ data versions V3O_N2O_8.0 and V3O_CH4_8.0 (in the following referred as V3O_8.0) and covers 45 days between 13 September 2002 and 21 October 2003. The second one (V3O_N2O_12.0 and V3O_CH4_12.0, in the following referred as V3O_12.0) was derived with an updated retrieval version and includes 54 days between 9 September 2003 and 25 March 2004. The retrieval updates applied to the latter data set include a weaker regularization of $\mathrm{N}_{2} \mathrm{O}$ at altitudes above $45 \mathrm{~km}$ in order to achieve a more realistic shape of the retrieved profiles in the presence of extraordinary mesospheric $\mathrm{N}_{2} \mathrm{O}$ enhancements such as those found in the aftermath of the 2003 "Halloween" SPE and the Arctic winter 2004. It should be noted, however, that above $60 \mathrm{~km}$, retrieved profiles of enhanced $\mathrm{N}_{2} \mathrm{O}$ tend to be low-biased in both data sets due to the regularization. In consequence, the peak altitudes of the derived mesospheric $\mathrm{N}_{2} \mathrm{O}$ enhancements could appear lower than in reality.

In order to analyze the retrieved trace gas profiles in a dynamical context, potential vorticity data from the European Centre for Medium-Range Weather Forecasts (ECMWF) analysis has been used for the representation of $\mathrm{N}_{2} \mathrm{O}$ and $\mathrm{CH}_{4}$ data in equivalent latitudes as described by Nash et al. (1996). 

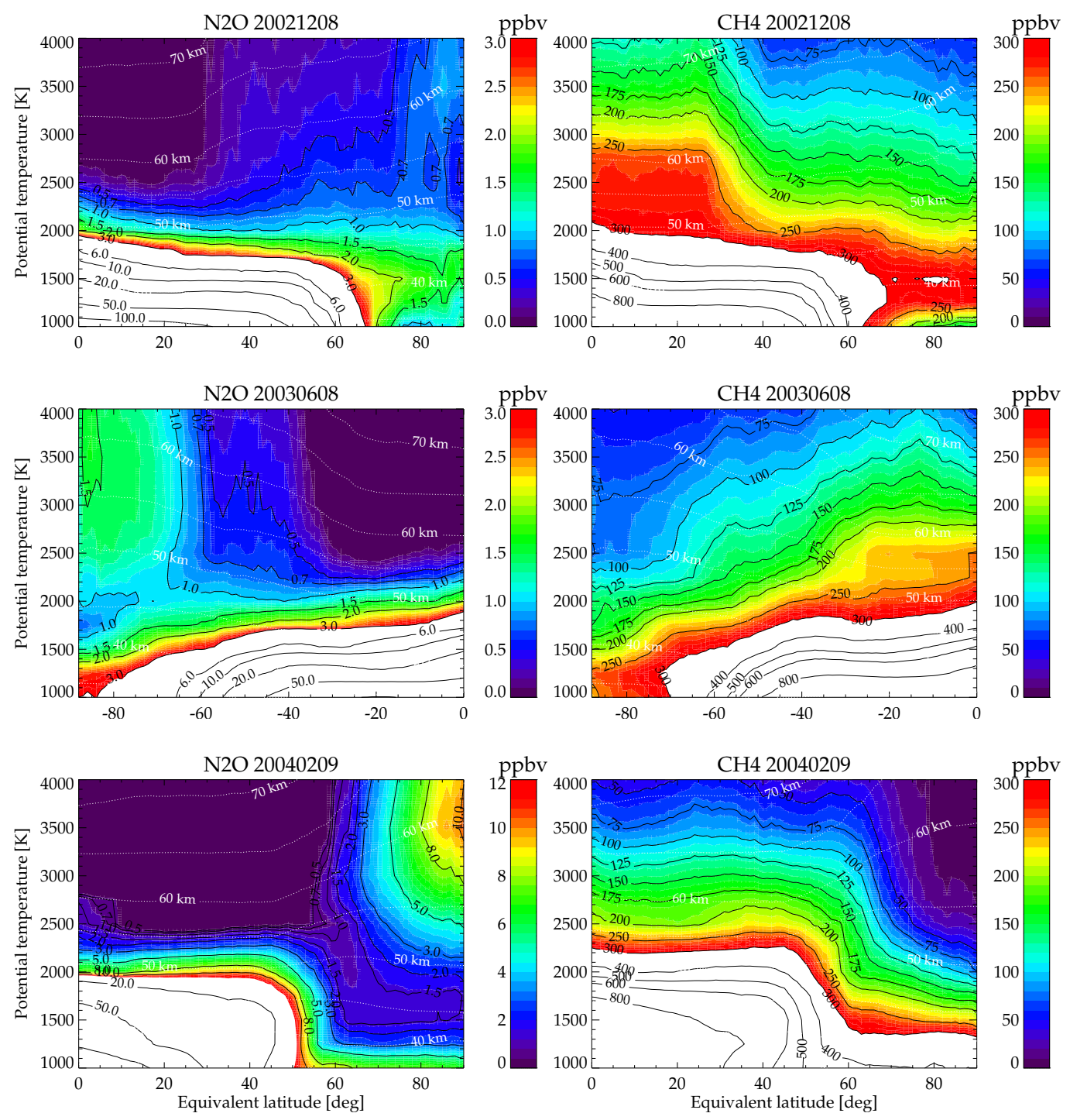

Fig. 1. Potential temperature-equivalent latitude daily mean cross sections of $\mathrm{N}_{2} \mathrm{O}$ (left) and $\mathrm{CH}_{4}$ (right) vmr retrieved by IMK/IAA for the NH for 8 December 2002 (top), SH for 8 June 2003 (middle), and NH for 9 February 2004 (bottom). Data versions used are V3O_8.0 (top and middle) and V3O_12.0 (bottom). Mean geometric heights are indicated by dotted white lines. Note the different scale in the bottom left panel.

Figure 1 shows potential temperature-equivalent latitude daily mean cross sections of $\mathrm{N}_{2} \mathrm{O}$ and $\mathrm{CH}_{4}$ vmr on representative days in the $\mathrm{NH}$ winter 2002/2003, SH winter 2003, and $\mathrm{NH}$ winter 2003/2004. Mesospheric polar winter $\mathrm{N}_{2} \mathrm{O}$ enhancements are clearly visible during all days, being most pronounced at equivalent latitudes higher than $60^{\circ}$. Their magnitudes, however, vary significantly, reaching $0.8,1.7$, and 10 ppbv on 8 December 2002, 8 June 2003, and 9 February 2004, respectively. The peak altitudes of the retrieved $\mathrm{N}_{2} \mathrm{O}$ enhancements are located around $60 \mathrm{~km}$. Due to regularization effects in the retrieval, however, it cannot be excluded that the true peak altitudes are located at higher alti- tudes. The corresponding $\mathrm{CH}_{4}$ distributions show generally low vmr values at the $\mathrm{N}_{2} \mathrm{O}$ peak positions which are typical for polar winter descent of mesospheric air. Further, lowest $\mathrm{CH}_{4}$ vmrs appeared on 9 February 2004 when highest $\mathrm{N}_{2} \mathrm{O}$ amounts were observed. This anti-correlation of $\mathrm{CH}_{4}$ and $\mathrm{N}_{2} \mathrm{O}$ at high latitudes cannot be explained by dynamics without invoking an upper atmospheric chemical source of $\mathrm{N}_{2} \mathrm{O}$. The latitudinal extension of the mesospheric $\mathrm{N}_{2} \mathrm{O}$ layer is much narrower in February 2004 than in the other winters, showing a pronounced gradient at $60^{\circ} \mathrm{N}$ equivalent latitude and background $\mathrm{N}_{2} \mathrm{O}$ abundances at lower latitudes. A strong gradient is also found in the $\mathrm{CH}_{4}$ distributions, although with 

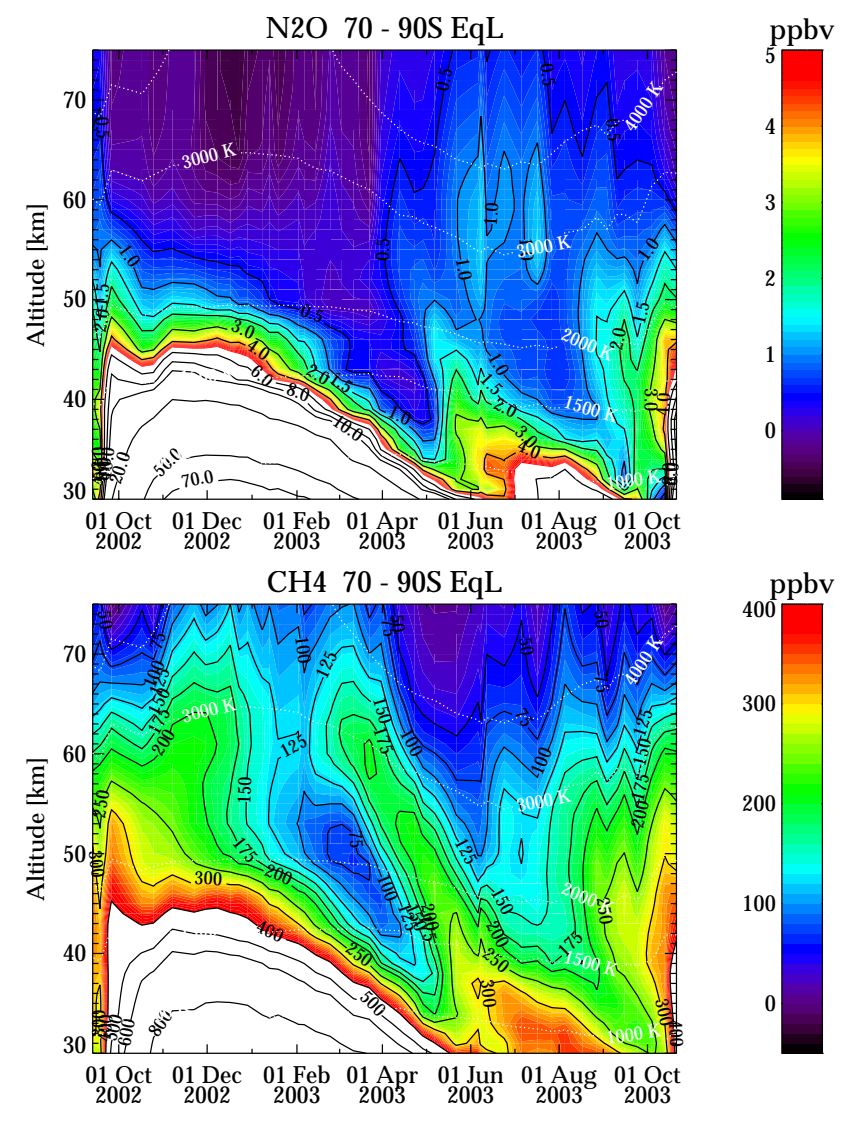

Fig. 2. Temporal evolution of $\mathrm{N}_{2} \mathrm{O}$ (top) and $\mathrm{CH}_{4}$ (bottom) VMR retrieved by IMK/IAA (Versions V3O_8.0) averaged over equivalent latitudes $70-90^{\circ} \mathrm{S}$ from September 2002 until October 2003. An area-weighting factor (cosine of equivalent latitude) has been applied. Mean potential temperatures are indicated by dotted white lines.

opposite sign, indicating that the polar vortex boundary was located at $60^{\circ} \mathrm{N}$ equivalent latitudes. Indeed, an unusual strong vortex together with a very fast and efficient descent of mesospheric air has been observed in this particular Arctic winter (Manney et al., 2005). $\mathrm{N}_{2} \mathrm{O}$ enhancements observed during the other two polar winters do not show such pronounced gradients and extend towards low latitudes, reaching background values around $30^{\circ}$. Thus, it seems that in the 2002-2003 winters stronger mixing of polar and tropical air occurred through a weaker polar vortex boundary.

Figure 2 shows the temporal evolution of mean $\mathrm{N}_{2} \mathrm{O}$ and $\mathrm{CH}_{4}$ abundances (Version V3O_8.0) within 70-90 $\mathrm{S}$ equivalent latitudes in the period September 2002 to November 2003. In September 2002, characterized by a major warming which led to a split of the stratospheric polar vortex (e.g., Newman and Nash, 2005), mesospheric $\mathrm{N}_{2} \mathrm{O}$ abundances around $0.5 \mathrm{ppbv}$ were observed. Given the unusual dynamical situation which allowed for intrusions of tropical air masses into the polar region, it is not clear whether these small $\mathrm{N}_{2} \mathrm{O}$ enhancements are of chemical or dynamical origin. The apparent descent visible in the temporal evolution of $\mathrm{N}_{2} \mathrm{O}$ and $\mathrm{CH}_{4}$ abundances during the following polar summer (i.e. December to April) is originated by photochemical losses of both species involving photolysis and reactions with $\mathrm{OH}$ and $\mathrm{O}\left({ }^{1} \mathrm{D}\right)$. Later on, a tongue of enhanced $\mathrm{CH}_{4}$ can be seen, localized around $60 \mathrm{~km}$ in March and descending to $30 \mathrm{~km}$ in July/August. These $\mathrm{CH}_{4}$ enhancements were generated by an accelerated Brewer-Dobson circulation with strong poleward transport of tropical air masses rich in $\mathrm{CH}_{4}$ preceding the downward motion during polar winter. The temporal evolution of $\mathrm{N}_{2} \mathrm{O}$ shows a similar behavior, though transport-generated $\mathrm{N}_{2} \mathrm{O}$ enhancements are less pronounced at altitudes above $50 \mathrm{~km}$ compared to the corresponding $\mathrm{CH}_{4}$ distributions. During June-August 2003, three $\mathrm{N}_{2} \mathrm{O}$ peaks reaching values higher than 1 ppbv show up at altitudes around $55-65 \mathrm{~km}$ while $\mathrm{CH}_{4}$ vmrs were generally low due to polar winter descent. As already seen in the $\mathrm{N}_{2} \mathrm{O}$ zonal mean distributions on 8 June, these $\mathrm{N}_{2} \mathrm{O}$ peaks are most likely related to chemical production. From August until the final breakup of the polar vortex in October, $\mathrm{CH}_{4}$ abundances started to increase above $40 \mathrm{~km}$ due to stronger mixing across a weakened vortex boundary (Funke et al., 2005). These intrusions of tropical air into the polar regions makes it more difficult to distinguish whether mesospheric $\mathrm{N}_{2} \mathrm{O}$ enhancements in August and September are related to chemistry or to transport.

The temporal evolution of mean $\mathrm{N}_{2} \mathrm{O}$ and $\mathrm{CH}_{4}$ abundances within $70-90^{\circ} \mathrm{N}$ equivalent latitudes are shown in Fig. 3 (Versions V3O_8.0 covering September 2002 to November 2003) and Fig. 4 (Versions V3O_12.0 covering September 2003 to March 2004). The general patterns of the temporal evolution of $\mathrm{CH}_{4}$ distributions in the $\mathrm{NH}$ are similar to the $\mathrm{SH}$, except that during the NH Arctic winters major warmings occurred which led to pronounced polar vortex excursions towards mid-latitudes and hence, to enhanced mixing of polar and tropical air masses in the stratosphere and mesosphere in January 2003 and 2004. In consequence, high $\mathrm{CH}_{4}$ vmrs were observed during these events. Several episodes of upper stratospheric and mesospheric $\mathrm{N}_{2} \mathrm{O}$ enhancements were found in the Arctic winters 2002-2004. In November/December 2002, enhancements of $0.5-0.8$ ppbv occurred around $60 \mathrm{~km}$. As already seen in the zonal mean distributions on 8 December 2002 (Fig. 1), these $\mathrm{N}_{2} \mathrm{O}$ enhancements went along with low $\mathrm{CH}_{4}$ vmrs and are thus most likely related to an upper atmospheric source. The mesospheric enhancements were interrupted by the warming event in January 2003, but showed up again in February inside of descending air masses with even lower $\mathrm{CH}_{4}$ vmrs than in December 2002. Similar as in the $\mathrm{SH}$, the $\mathrm{NH}$ polar summer 2003 was characterized by mesospheric air masses very poor in $\mathrm{N}_{2} \mathrm{O}$.

The temporal evolution of $\mathrm{N}_{2} \mathrm{O}$ in the Arctic winter 2003/2004 (Fig. 4) was rather unusual due to the "Halloween" solar proton event which led to efficient and 

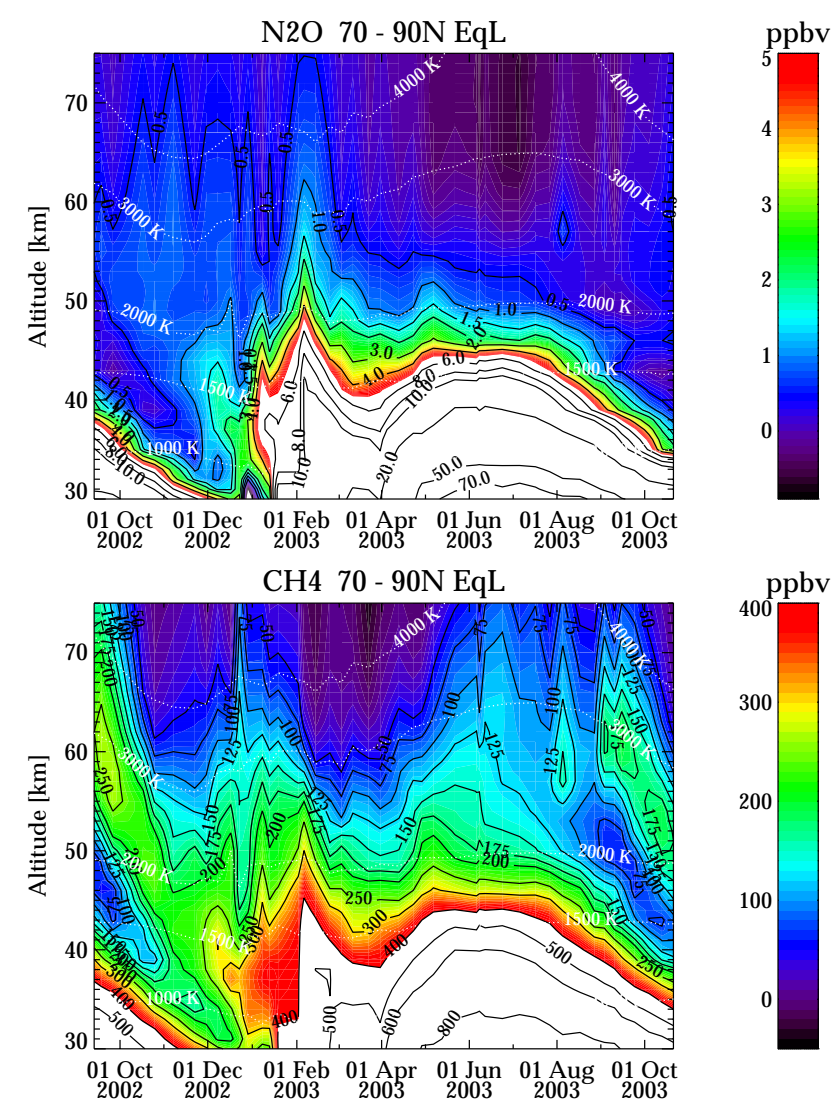

Fig. 3. As Fig. 2, but for equivalent latitudes $70-90^{\circ} \mathrm{N}$.

instantaneous $\mathrm{N}_{2} \mathrm{O}$ production by Reaction (R1) of up to $5 \mathrm{ppbv}$ in the $50-70 \mathrm{~km}$ region on 29 October 2003 . As discussed in detail in Funke et al. (2008), these $\mathrm{N}_{2} \mathrm{O}$ enhancements descended with the meridional circulation in the following weeks down to $40 \mathrm{~km}$. Several smaller enhancements (up to 2 ppbv) occurred around $60 \mathrm{~km}$ in the second half of November and mid-December which cannot be attributed to SPEs. These enhancements disappeared by the end of December during the major warming event. Around 15 January 2004, mesospheric $\mathrm{N}_{2} \mathrm{O}$ abundances started suddenly to increase to values up to $7 \mathrm{ppbv}$ (see also Fig. 1, lower left panel), coinciding with the period where strongest polar winter descent occurred. These air masses rich in $\mathrm{N}_{2} \mathrm{O}$ of chemical origin descended down to altitudes around $45 \mathrm{~km}$ until end of March 2004. Unfortunately, a further evaluation of the $\mathrm{N} 2 \mathrm{O}$ temporal evolution was not possible since MIPAS observations ceased on 26 March 2004 due to an instrumental failure.

\subsection{Analysis of ESA-generated $\mathrm{N}_{2} \mathrm{O}$ data}

Since episode-based scientific MIPAS-IMK-IAA data are available only for selected days, we have also analyzed the operational ESA $\mathrm{N}_{2} \mathrm{O}, \mathrm{NO}_{2}$, and $\mathrm{CH}_{4}$ data (reprocessed data
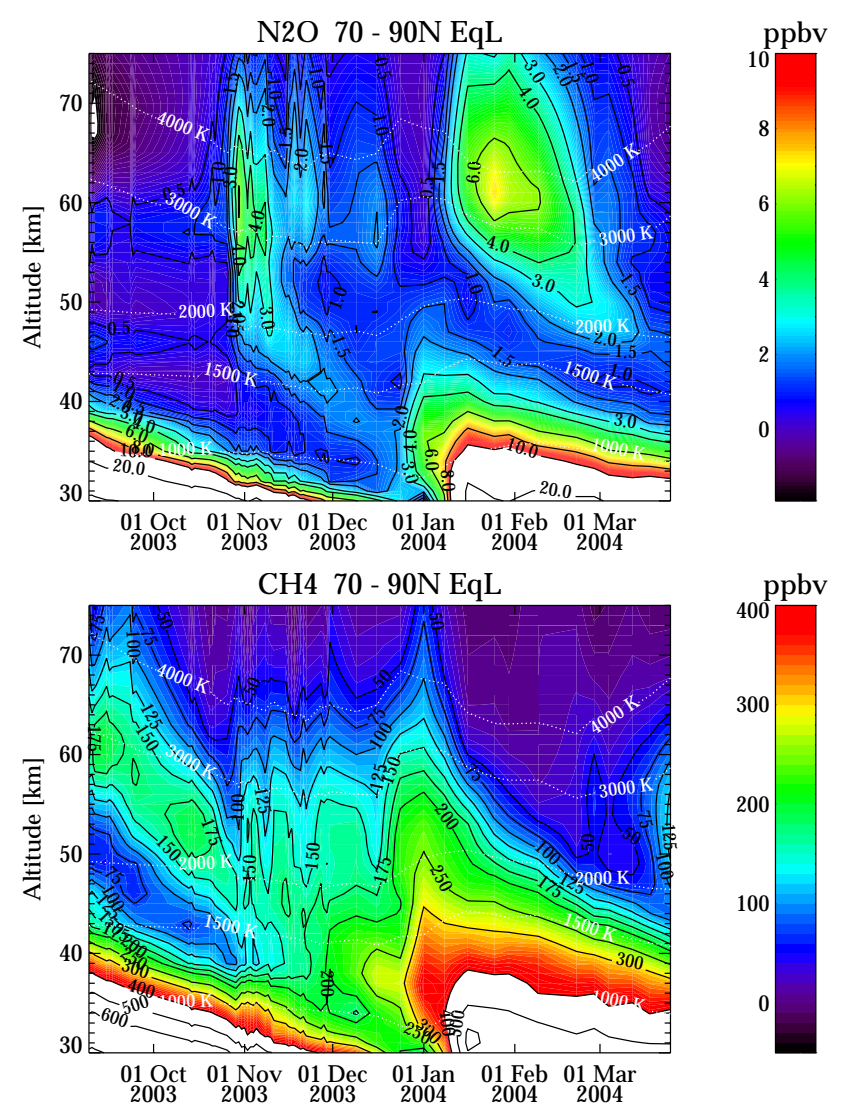

Fig. 4. Temporal evolution of $\mathrm{N}_{2} \mathrm{O}$ (top) and $\mathrm{CH}_{4}$ (bottom) VMR retrieved by IMK/IAA (Versions V3O_12.0) averaged over equivalent latitudes $70-90^{\circ} \mathrm{N}$ from September 2003 until March 2004. An area-weighting factor (cosine of equivalent latitude) has been applied. Mean potential temperatures are indicated by dotted white lines.

version 4.61/4.62). This further allows to corroborate the evidence for chemically-produced mesospheric $\mathrm{N}_{2} \mathrm{O}$ enhancements found in the IMK/IAA data with data generated with an independent retrieval algorithm and, hence to exclude retrieval artifacts as a possible explanation. ESA data are retrieved with the operational retrieval algorithm as described by Raspollini et al. (2006) at the MIPAS tangent heights. Retrieved $\mathrm{N}_{2} \mathrm{O}$ abundances on the highest tangent height level are discarded by the operational algorithm, such that highest available $\mathrm{N}_{2} \mathrm{O}$ observations are taken around $60 \mathrm{~km}$ with variations of $\pm 2 \mathrm{~km}$ related to the orbital characteristics. ESA 4.61/4.62 data include all MIPAS observations taken with full spectral resolution between June 2002 and March 2004, representing thus a quasi-continuous data set. Here, we analyze operational $\mathrm{N} 2 \mathrm{O}$ data interpolated to an altitude of $58 \mathrm{~km}$, which turned out to be the highest altitude covered by this data set during the whole period. However, care has to be taken when statistically analyzing ESA data products (i.e. zonal mean values) which are close to the detection limit 

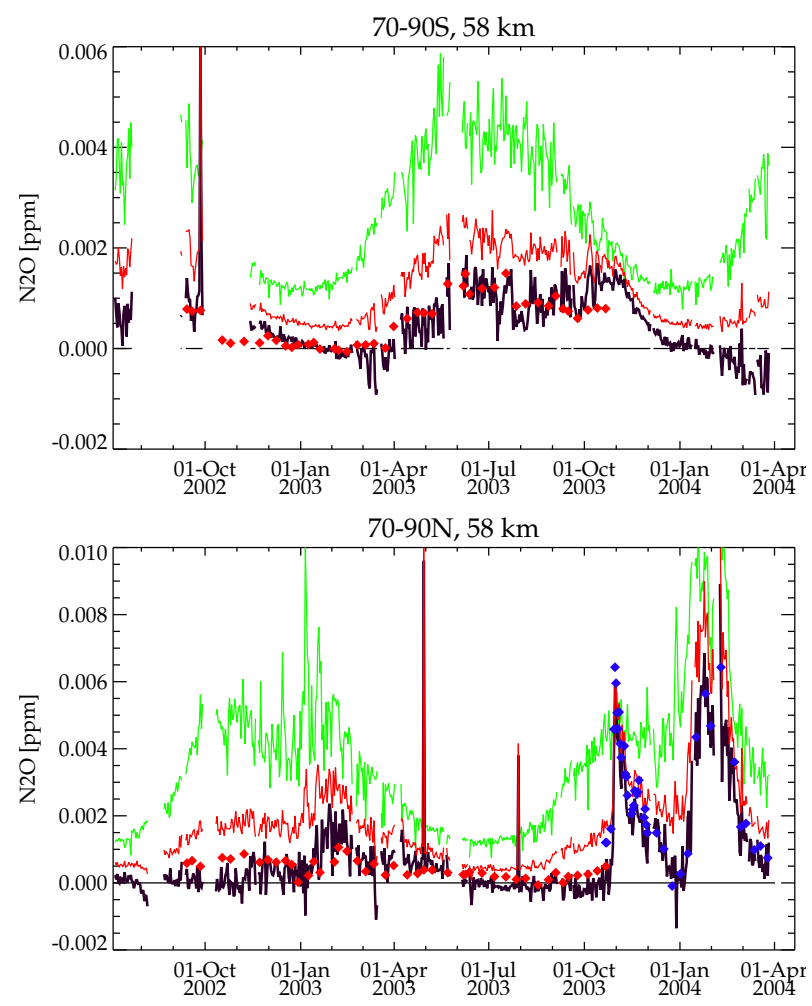

Fig. 5. $70-90^{\circ} \mathrm{S}$ (top) and $70-90^{\circ} \mathrm{N}$ (bottom) averages of ESA $\mathrm{N}_{2} \mathrm{O}$ vmr (reprocessed data version 4.61/4.62) with and without statistical correction (black and red solid lines, respectively), single measurement noise errors (green solid line), and $\mathrm{N}_{2} \mathrm{O}$ vmr retrieved at IMK/IAA (Versions V3O_8.0 and V3O_12.0 shown by red and blue diamonds, respectively) at $58 \mathrm{~km}$. Spikes in the $\mathrm{N}_{2} \mathrm{O}$ averages on 26 September 2002 (SH), 29 April 2003 (NH), and 29 July 2003 $(\mathrm{NH})$ are generated by spurious data.

since negative vmrs are not supported by this retrieval algorithm. Whenever negative vmrs occur at a given altitude during an iteration of the retrieval, the corresponding vmr profile points are set arbitrarily to a value of $10^{-10} \mathrm{ppmv}$. The rationale of this procedure is to avoid numerical retrieval instabilities. This truncation of negative values, however, results in a positive bias of ESA vmr mean values, if the "true" mean value is close to the noise error or below. In order to correct for this bias, the following procedure was applied: Assuming zonal homogeneity at a given altitude and a Gaussian distribution of $\mathrm{N}_{2} \mathrm{O}$ measurements affected by random errors, the expectation value $\varepsilon$ of all truncated negative values to be zonally averaged can be determined by

$\varepsilon=\int_{-\infty}^{0} \frac{x}{\sigma \sqrt{2 \pi}} \exp \left[-\frac{\left(x-x_{0}\right)^{2}}{2 \sigma^{2}}\right] d x$,

where $x_{0}$ is the "true" zonal mean value and $\sigma$ is the standard deviation assumed to be identical to the zonally averaged noise error. After determination of $\varepsilon$ by resolving numeri- cally the integral in Eq. (1), the corrected zonal mean can be calculated by substitution of all truncated profile points by $\varepsilon$ and subsequent averaging. Since the "true" zonal mean value is unknown at the beginning, we start with the uncorrected value and iterate until $x_{0}$ changes by less than $2 \%$. This convergence criterion was usually fulfilled after a few iterations.

Figure 5 shows the temporal evolution of ESA $\mathrm{N}_{2} \mathrm{O}$ vmr averaged within $70-90^{\circ}$ geographical latitudes at $58 \mathrm{~km}$ before and after the statistical correction, together with IMK/IAA-retrieved $\mathrm{N}_{2} \mathrm{O}$ averages and mean single measurement noise errors. Excellent agreement between the corrected averaged ESA and IMK/IAA data is found, while the uncorrected ESA data shows a positive bias up to $1.2 \mathrm{ppbv}$ in dependence of the noise error. We thus conclude that the statistical correction applied to the zonally averaged ESA $\mathrm{N}_{2} \mathrm{O}$ works satisfactorily. It can further be excluded that the $\mathrm{N}_{2} \mathrm{O}$ enhancements discussed in the previous section are generated by a retrieval artifact in any of the data sets, given that they appear with good quantitative agreement in two independently retrieved data sets.

\section{Analysis of $\mathrm{N}_{2} \mathrm{O}-\mathrm{CH}_{4}$ correlations}

In the tropics and middle latitudes, $\mathrm{N}_{2} \mathrm{O}$ and $\mathrm{CH}_{4}$ show compact correlations, only varying little between seasons and years (Michelsen et al., 1998a,b). $\mathrm{N}_{2} \mathrm{O}$ vmrs generally increase monotonically with increasing $\mathrm{CH}_{4}$ with a non-linear relationship. In polar spring, this relationship tends to be more linear due to mixing of subsided vortex air and midlatitude air masses. Without mesospheric sources, $\mathrm{N}_{2} \mathrm{O}$ should increase with $\mathrm{CH}_{4}$ in any case, while the presence of such source should invert this dependence for low $\mathrm{CH}_{4}$ vmrs. Therefore, $\mathrm{N}_{2} \mathrm{O}-\mathrm{CH}_{4}$ correlations represent an excellent tool for the detection of mesospheric $\mathrm{N}_{2} \mathrm{O}$ sources.

We have analyzed $\mathrm{N}_{2} \mathrm{O}-\mathrm{CH}_{4}$ correlations determined from ESA data on a monthly basis, using all available observations between $45 \mathrm{~km}$ and $60 \mathrm{~km}$ within $60-90^{\circ} \mathrm{S}$ and 60 $90^{\circ} \mathrm{N}$. We first performed a histogramming of the observations within bins of $\Delta \mathrm{CH}_{4}=10 \mathrm{ppbv}$ and $\Delta \mathrm{N}_{2} \mathrm{O}=0.1 \mathrm{ppbv}$. Median values of the obtained $\mathrm{N}_{2} \mathrm{O}$ probability density function (PDF) at a given $\mathrm{CH}_{4}$ level were then determined in a second step.

Figure 6 shows the obtained temporal evolution of the $\mathrm{N}_{2} \mathrm{O}-\mathrm{CH}_{4}$ correlation for $60-90^{\circ} \mathrm{S}$ and $60-90^{\circ} \mathrm{N}$. Deviations from the typical correlation, characterized by monotonically increasing $\mathrm{N}_{2} \mathrm{O}$ with $\mathrm{CH}_{4}$, are clearly visible in all four polar winters at $\mathrm{CH}_{4}$ levels below $0.1 \mathrm{ppmv}$, providing an additional proof for mesospheric $\mathrm{N}_{2} \mathrm{O}$ sources. Maximum median values of the $\mathrm{N}_{2} \mathrm{O}$ PDFs of 2.2 and $4 \mathrm{ppbv}$ are found at the lowest $\mathrm{CH}_{4}$ levels during June 2003 in the SH and January 2004 in the NH, respectively. During these months, a pronounced anti-correlation of $\mathrm{N}_{2} \mathrm{O}$ and $\mathrm{CH}_{4}$ below $0.1 \mathrm{ppmv}$ was observed. During the Antarctic winter 
2002 and Arctic winter 2002/2003, deviations from the typical correlation were less pronounced. In these winters, maximum median values of the $\mathrm{N}_{2} \mathrm{O}$ PDFs of $1 \mathrm{ppbv}$ are found at $\mathrm{CH}_{4}$ levels of $0.03-0.05$ ppmv.

A further anomaly is found during November 2003 in the $\mathrm{NH}$, when $\mathrm{N}_{2} \mathrm{O}$ was significantly increased after the "Halloween" SPE. In contrast to the perturbed polar winter correlations discussed above, however, enhanced $\mathrm{N}_{2} \mathrm{O}$ is found at nearly all $\mathrm{CH}_{4}$ levels. This is expected, since solar protons led to in situ production of $\mathrm{N}_{2} \mathrm{O}$ at altitudes above $45 \mathrm{~km}$. The fact that polar winter episodes of enhanced $\mathrm{N}_{2} \mathrm{O}$ are characterized by inverted $\mathrm{N}_{2} \mathrm{O}-\mathrm{CH}_{4}$ correlations at $\mathrm{CH}_{4}$ levels smaller than 0.5 ppbv hints thus at descent of air masses enriched in $\mathrm{N}_{2} \mathrm{O}$ from higher altitudes rather than in situ production.

Increased median values of $\mathrm{N}_{2} \mathrm{O}$ PDFs at $\mathrm{CH}_{4}$ levels higher than $0.1 \mathrm{ppmv}$ are not only found in the aftermath of the "Halloween" SPE. Tongues of high $\mathrm{N}_{2} \mathrm{O}$ are visible during July 2002, June 2003, and September 2003 in the SH, as well as February 2003 and January 2004 in the NH. Such enhancements hint at mixing of descended $\mathrm{N}_{2} \mathrm{O}$-rich and $\mathrm{CH}_{4}$ poor mesospheric air masses with ambient air masses from lower latitudes.

The finding that chemical production of $\mathrm{N}_{2} \mathrm{O}$ occurred in the mesosphere during all polar winters in the period 20022004, though with variable magnitude, makes it rather unlikely that mesospheric $\mathrm{N}_{2} \mathrm{O}$ enhancements are sporadic singular phenomena. It is further evident that polar $\mathrm{N}_{2} \mathrm{O}-\mathrm{CH}_{4}$ correlations are significantly perturbed by this mesospheric $\mathrm{N}_{2} \mathrm{O}$ source.

\section{Discussion}

In order to understand which are the chemical mechanisms responsible for the observed polar winter $\mathrm{N}_{2} \mathrm{O}$ enhancements and which are the atmospheric parameters affecting their magnitudes and inter-annual variations, we have assessed the temporal evolutions of polar mesospheric $\mathrm{N}_{2} \mathrm{O}$, $\mathrm{CH}_{4}$, and $\mathrm{NO}_{2}$ at $58 \mathrm{~km}$ from the ESA data set, jointly with precipitating electron fluxes observed by the Medium Energy Proton and Electron Detector (MEPED) on NOAA 16 (poes.ngdc.noaa.gov/data/avg) and calculated ion pair production rates due to solar protons (Jackman et al., 2008).

The temporal evolution of these quantities are shown in Figs. 7 and 8 for the $\mathrm{SH}$ and $\mathrm{NH}$, respectively. In order to isolate the $\mathrm{N}_{2} \mathrm{O}$ amount generated by the mesospheric source from the contribution of $\mathrm{N}_{2} \mathrm{O}$ of tropospheric origin, we have estimated the latter by applying a typical $\mathrm{N}_{2} \mathrm{O}-\mathrm{CH}_{4}$ correlation to the $\mathrm{CH}_{4}$ observations. This correlation has been determined from an average of the monthly $\mathrm{N}_{2} \mathrm{O}-\mathrm{CH}_{4}$ correlations presented above, excluding the polar winter periods (JuneSeptember in the SH and November-February in the $\mathrm{NH}$ ) perturbed by mesospheric $\mathrm{N}_{2} \mathrm{O}$ generation. A dominant contribution of tropospheric $\mathrm{N}_{2} \mathrm{O}$ transported up to $58 \mathrm{~km}$ was

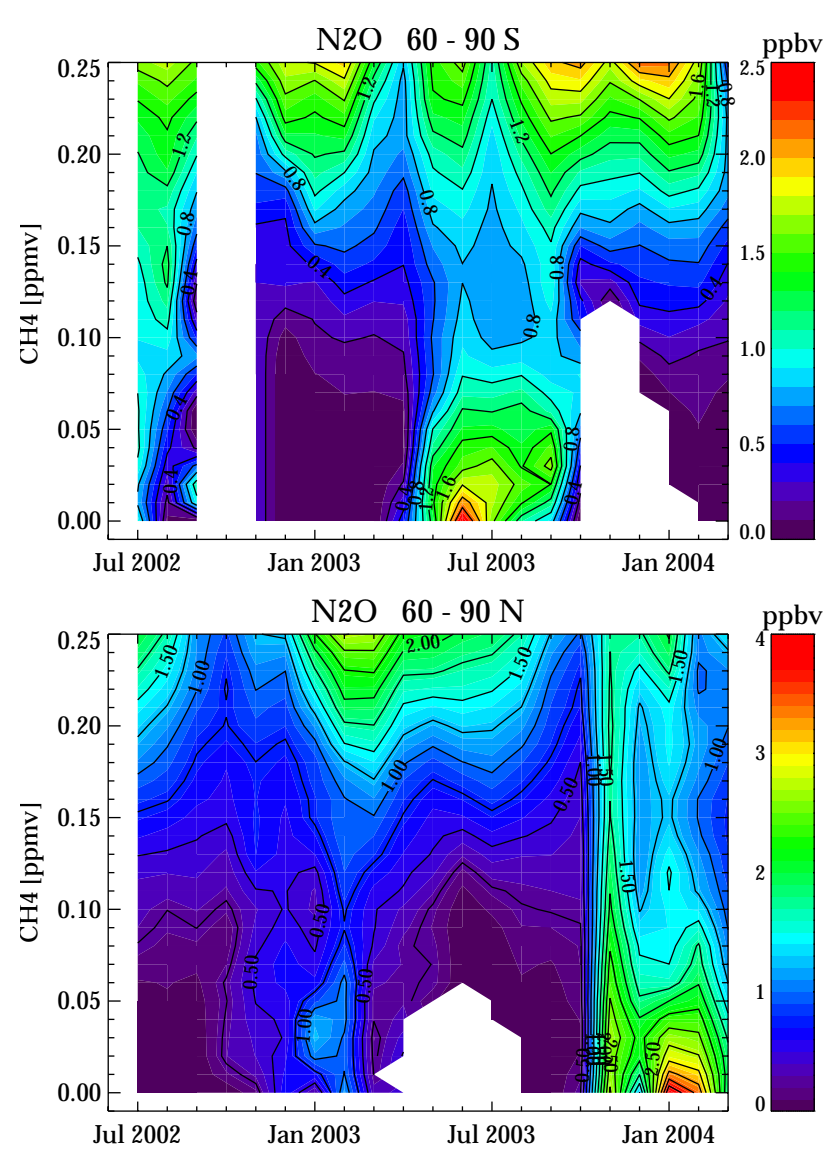

Fig. 6. Monthly mean median values of $\mathrm{N}_{2} \mathrm{O}$ PDFs at given $\mathrm{CH}_{4}$ levels calculated from ESA 4.61/4.62 data products for $60-90^{\circ} \mathrm{S}$ (top) and $60-90^{\circ} \mathrm{N}$ (bottom). White regions reflect an availability of less then 30 observations at the corresponding $\mathrm{CH}_{4}$ level. Note the different color scales for $\mathrm{SH}$ and $\mathrm{NH}$ !

found in the SH polar regions from September 2002 to December 2002 and from October 2003 to January 2004. In the $\mathrm{NH}$, we found smaller amounts of tropospheric $\mathrm{N}_{2} \mathrm{O}$ with dominant contributions during the major warming in January 2003 and from April to May 2003. Except for these episodes, $\mathrm{N}_{2} \mathrm{O}$ observed at $58 \mathrm{~km}$ was produced near entirely by the mesospheric source.

Possible mesospheric $\mathrm{N}_{2} \mathrm{O}$ production mechanisms based on Reactions (R1) and (R2) rely on the availability of atomic nitrogen or metastable $\mathrm{N}_{2}\left(\mathrm{~A}^{3} \Sigma_{u}^{+}\right)$, which are both largely enhanced during episodes of energetic particle precipitation. It has already been demonstrated by Funke et al. (2008) that the $\mathrm{N}_{2} \mathrm{O}$ enhancements observed after the 2003 "Halloween" SPE in the Arctic stratosphere and lower mesosphere were generated locally by Reaction (R1) in the presence of enhanced $\mathrm{N}$ produced under the impact of solar protons. In the following discussion, we focus on the other $\mathrm{N}_{2} \mathrm{O}$ enhancements observed in the polar winters during 2002-2004. In order to assess whether solar protons could have played a 

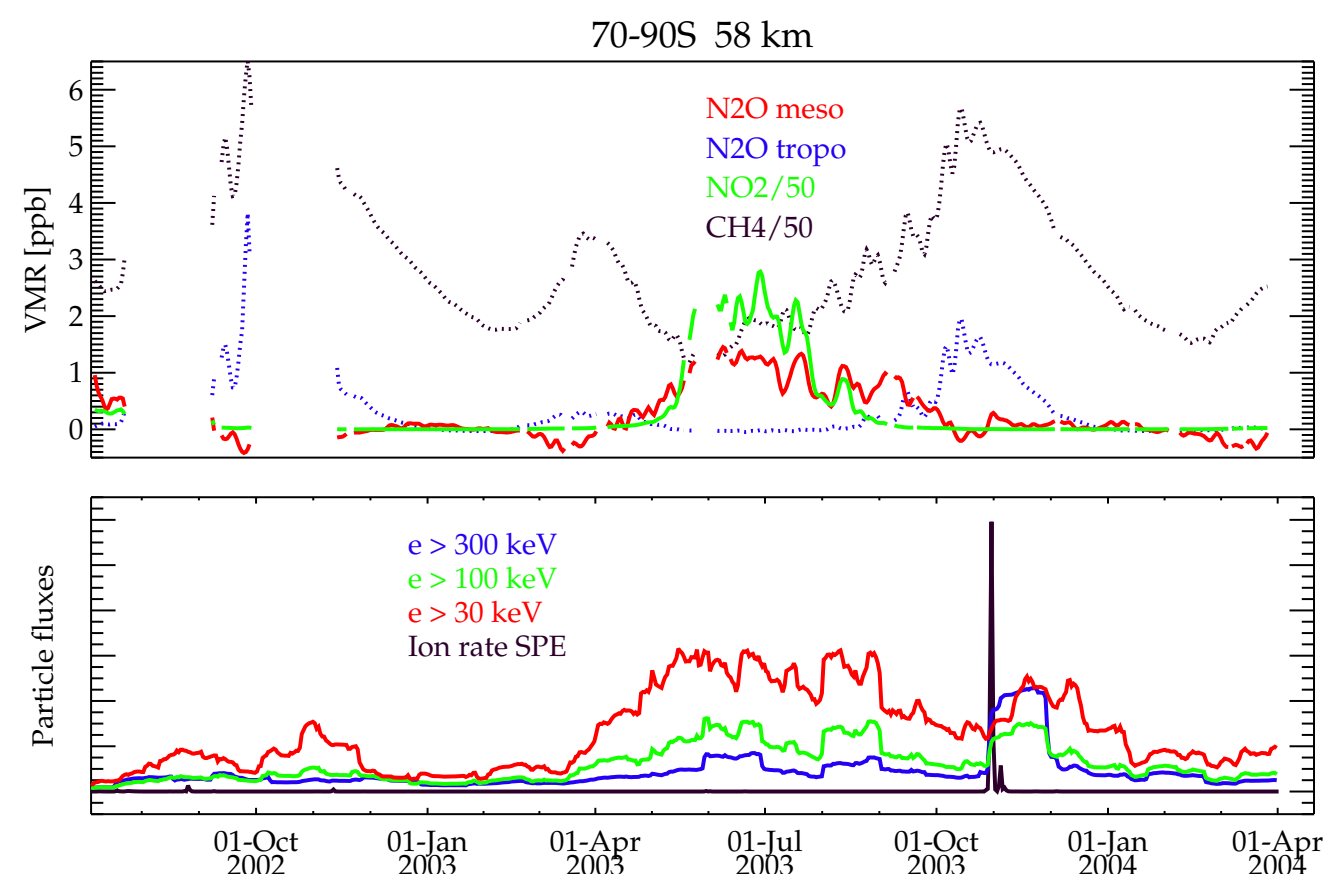

Fig. 7. Upper panel: Smoothed temporal evolution of the estimated mesospheric (solid red) and tropospheric (dotted blue) contributions to the observed $\mathrm{N}_{2} \mathrm{O}$ vmr, as well as $\mathrm{NO}_{2}$ (solid green) and $\mathrm{CH}_{4}$ (dotted black) vmrs (corrected ESA data) at 58 km averaged over 70-90 $\mathrm{S}$. Note that $\mathrm{NO}_{2}$ and $\mathrm{CH}_{4}$ vmrs are scaled by a factor of 0.02 . Lower panels: 30-day averages of integral precipitating electron fluxes within $\mathrm{L}>2.5$ and $60-90^{\circ} \mathrm{S}$ with energies $>30 \mathrm{keV}$ (red), $>100 \mathrm{keV}$ (green), and $>300 \mathrm{keV}$ (blue) as measured by the MEPED instrument on NOAA. Atmospheric ionization rates at $0.3 \mathrm{hPa}$ due to solar protons from Jackman et al. (2008) are also shown (black). Units are arbitrary.
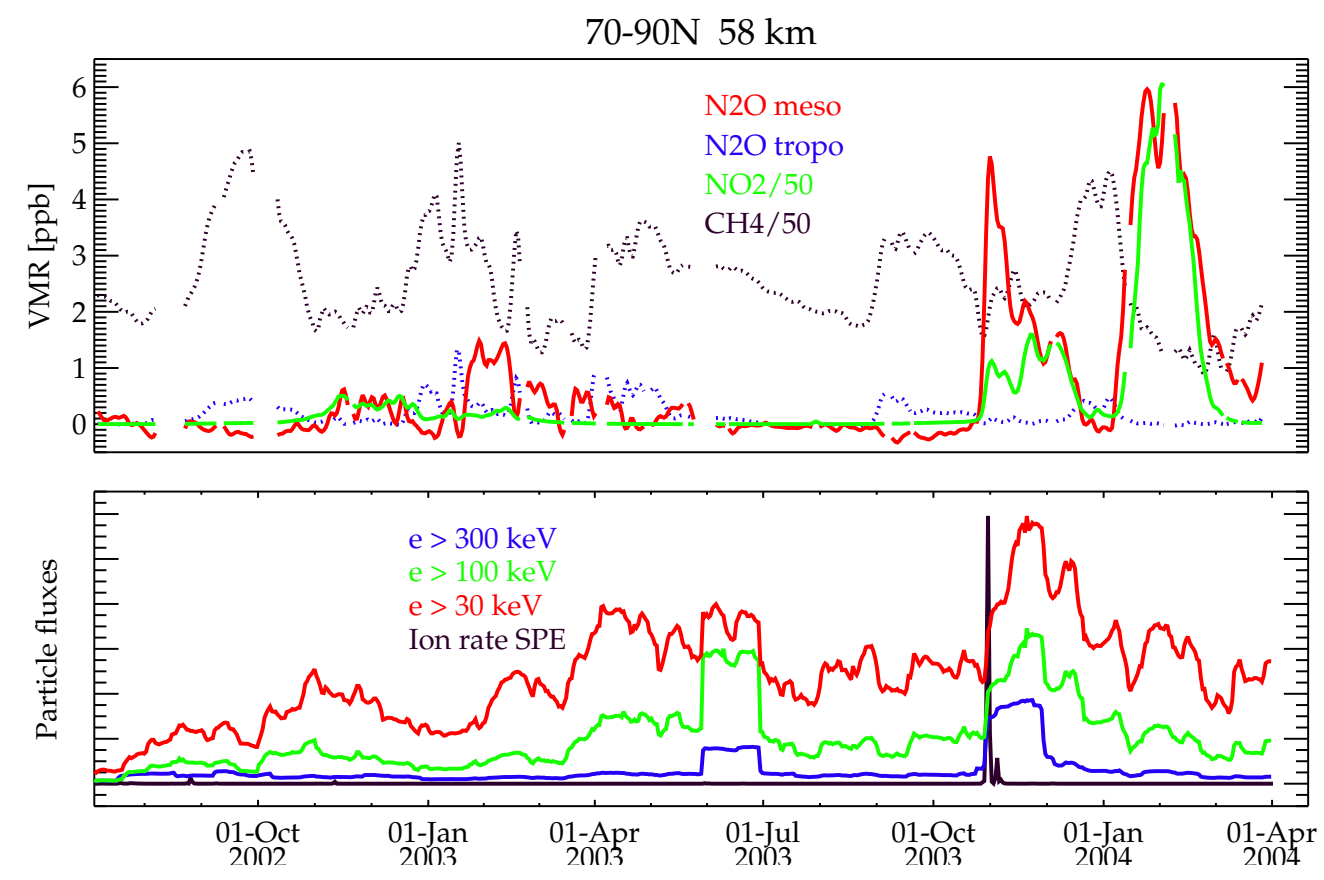

Fig. 8. As Fig. 7, but for $70-90^{\circ} \mathrm{N}$. 
role in these $\mathrm{N}_{2} \mathrm{O}$ enhancements, we looked for other SPEs during this period. However, the atmospheric ionization rates due to solar protons at $0.3 \mathrm{hPa}$ (Figs. 7 and 8, lower panels), which represent a direct measure of SPE-induced N production, shows only very small peaks apart from the OctoberNovember 2003 event. It is thus very unlikely that SPEinduced $\mathrm{N}_{2} \mathrm{O}$ production had significantly contributed to the observed $\mathrm{N}_{2} \mathrm{O}$ enhancements under discussion.

A further source of enhanced $\mathrm{N}$ or $\mathrm{N}_{2}\left(\mathrm{~A}^{3} \Sigma_{u}^{+}\right)$could be energetic electron precipitation (EEP). Precipitating electron fluxes of different energies observed by the MEPED instrument are shown in Figs. 7 and 8 (lower panels). These fluxes have been averaged over a 30-day period in order to reflect that $\mathrm{N}_{2} \mathrm{O}$ losses are very small during polar winter and EEPinduced $\mathrm{N}_{2} \mathrm{O}$ production would therefore tend to accumulate. Fluxes of precipitating electrons of energies $30 \mathrm{keV}, 100 \mathrm{keV}$ and $300 \mathrm{keV}$ included in Figs. 7 and 8 cause ionization peaks at altitudes around 85,75 , and $60 \mathrm{~km}$, respectively (Callis et al., 1998). Therefore, they can be used as indicator for EEP-induced atmospheric ionization at these altitudes. Since only relative temporal variations of these fluxes are of interest when comparing them to the evolution of polar winter $\mathrm{N}_{2} \mathrm{O}$ enhancements, fluxes of different energies have been scaled arbitrarily for the sake of a better representation. Electron flux increases coincident with SPEs (i.e., 29 May and 29 October 2003) should be interpreted with caution since MEPED electron measurements are compromised by the presence of protons (Evans and Greer, 2000), although SPEs are thought to be associated with elevated electron fluxes inside the polar caps (e.g., Baker et al., 2004).

It becomes evident from Figs. 7 and 8 that strongest $\mathrm{N}_{2} \mathrm{O}$ enhancements at $58 \mathrm{~km}$ occur in polar winters with highest electron precipitation, i.e. the Antarctic winter 2003 and the Arctic winter 2004. The correlated inter-annual variations of mesospheric $\mathrm{N}_{2} \mathrm{O}$ and electron fluxes hint at an implication of EEP in the production of $\mathrm{N}_{2} \mathrm{O}$. On the other hand, no temporal correlation of the $\mathrm{N}_{2} \mathrm{O}$ evolution with the short-term fluctuations in any of the electron fluxes is visible. This suggests that a dominant local contribution of an EEP-related source at altitudes as low as $58 \mathrm{~km}$ is rather unlikely.

$\mathrm{N}_{2} \mathrm{O}$ enhancements of mesospheric origin seem to occur always in presence of elevated $\mathrm{NO}_{2}$, although the observed $\mathrm{NO}_{2}$ vmrs vary drastically from winter to winter (see Figs. 7 and 8, upper panels). This could hint at an implication of $\mathrm{NO}_{2}$ in the chemical production of $\mathrm{N}_{2} \mathrm{O}$. On the other hand, mesospheric $\mathrm{NO}_{2}$ enhancements during polar winters are known to be generated by descent of upper atmospheric $\mathrm{NO}_{\mathrm{x}}$ produced by energetic particle precipitation (Callis et al., 1998; Siskind, 2000; Funke et al., 2005; Randall et al., 2007). Then, the simultaneous occurrence of both species could simply reflect that their sources are located above the observed altitude $(58 \mathrm{~km})$ and their descended contributions are modulated by the meridional circulation in the same manner. A common modulation of $\mathrm{N}_{2} \mathrm{O}$ and $\mathrm{NO}_{2}$ by variable descent velocities and horizontal mix- ing is further supported by the good temporal correlation of small-scale structures in the evolution of both species which, in turn, is anti-correlated with the evolution of $\mathrm{CH}_{4} \mathrm{vmrs}$. It is also evident from Figs. 7 and 8 that polar winter enhancements of $\mathrm{N}_{2} \mathrm{O}$ are by far not proportional to the available $\mathrm{NO}_{2}$ amounts. The average $\mathrm{N}_{2} \mathrm{O} / \mathrm{NO}_{2}$ ratios observed during the periods with strongest $\mathrm{N}_{2} \mathrm{O}$ enhancements, i.e. in June-August 2003 in the SH and January-March 2004 in the $\mathrm{NH}$, were considerably smaller than those observed in periods with weak $\mathrm{N}_{2} \mathrm{O}$ enhancements. Further, mesospheric $\mathrm{N}_{2} \mathrm{O}$ enhancements tended to start earlier and lasted longer than the $\mathrm{NO}_{2}$ enhancements.

In order to qualitatively assess the relative magnitudes and peak altitudes of the EEP-related $\mathrm{N}_{2} \mathrm{O}$ sources, we have estimated $\mathrm{N}_{2} \mathrm{O}$ production rates due to Reactions (R1) and (R2) for different atmospheric conditions.

$\mathrm{N}\left({ }^{4} \mathrm{~S}\right)$ is generated in presence of EEP by a chain of ionization processes from $\mathrm{N}_{2}$. It is commonly assumed that each ion pair produced by electron impact leads to the formation of $0.55 \mathrm{~N}\left({ }^{4} \mathrm{~S}\right)$ atoms (e.g., Jackman et al., 2005). During night, this mechanism represents the only source of $\mathrm{N}\left({ }^{4} \mathrm{~S}\right)$, while at daytime, NO photolysis leads to additional $\mathrm{N}$ production. The dominating losses of atomic nitrogen are

$\mathrm{N}+\mathrm{NO} \rightarrow \mathrm{N}_{2}+\mathrm{O}$,

$\mathrm{N}+\mathrm{O}_{2} \rightarrow \mathrm{NO}+\mathrm{O}$

and Reaction (R1). Assuming atomic nitrogen to be in steady state and an efficiency of Reaction (R1) to form $\mathrm{N}_{2} \mathrm{O}$ of 0.5 (Funke et al., 2008), the $\mathrm{N}_{2} \mathrm{O}$ production rate $P_{1}$ due to Reaction (R1) is

$P_{1}=\frac{0.5 \times\left(0.55 p+J_{\mathrm{NO}}[\mathrm{NO}]\right) \times k_{1}\left[\mathrm{NO}_{2}\right]}{k_{3}[\mathrm{NO}]+k_{4}\left[\mathrm{O}_{2}\right]+k_{1}\left[\mathrm{NO}_{2}\right]}$,

where $p$ is the ion pair production rate, $J_{\mathrm{NO}}$ the photolysis rate of $\mathrm{NO}$, and $k_{1}, k_{3}$, and $k_{4}$ are the rate coefficients for the atomic nitrogen loss Reactions (R1), (R3), and (R4), respectively.

$\mathrm{N}_{2}\left(\mathrm{~A}^{3} \Sigma_{u}^{+}\right)$is also produced by the impact of precipitating electrons. Quenching by atomic oxygen, i.e.

$\mathrm{N}_{2}\left(\mathrm{~A}^{3} \Sigma_{u}^{+}\right)+\mathrm{O} \rightarrow \mathrm{N}_{2}+\mathrm{O}$,

and radiative emissions in the Vegard-Kaplan bands with an Einstein coefficient of $0.52 \mathrm{~s}^{-1}$ are the prominent losses in the thermosphere, while at lower altitudes Reaction (R2) becomes dominant. As reported by Zipf and Prasad (1980), we assume that each ion pair produces 0.35 metastable $\mathrm{N}_{2}\left(\mathrm{~A}^{3} \Sigma_{u}^{+}\right)$molecules. In accordance with the more recent laboratory work of de Sousa et al. (1985), we apply an efficiency of 0.02 to form $\mathrm{N}_{2}$ in Reaction (R2) as an upper limit. The $\mathrm{N}_{2} \mathrm{O}$ production rate $P_{2}$ due to Reaction (R2) is then

$P_{2}=\frac{0.02 \times 0.35 p \times k_{2}\left[\mathrm{O}_{2}\right]}{k_{2}\left[\mathrm{O}_{2}\right]+k_{5}[\mathrm{O}]+0.52}$, 

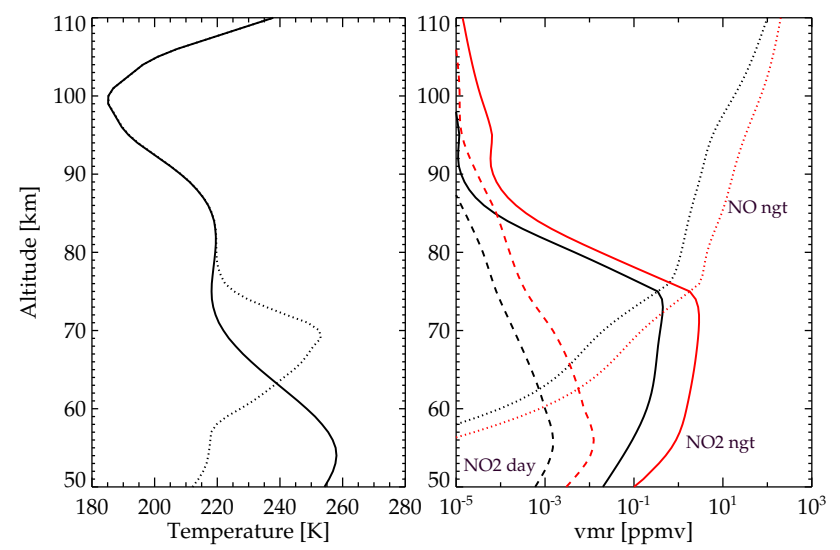

Fig. 9. Left: Kinetic temperatures used in the nominal (solid line) and "strong descent" (dotted line) scenario. Right: Volume mixing ratios of $\mathrm{NO}_{2}$ and $\mathrm{NO}$ during polar night (solid and dotted lines, respectively) and $\mathrm{NO}_{2}$ during day (dashed line) used in the nominal (black) and in the "high $\mathrm{NO}_{\mathrm{x}}$ " scenario (red).

where $k_{2}$ and $k_{5}$ are the rate coefficients for the Reactions (R2) and (R5), respectively.

As a representative profile of atmospheric ionization due to EEP, we took the average ion pair formation rates calculated by Callis et al. (1998) from MEPED data taken in the period 1979-1987 (see Fig. 2a of their work). These rates might underestimate the EEP-induced ionization for conditions of elevated geomagnetic activity as encountered during 2003. On the other hand, due to the averaging over nearly an entire solar cycle, they are useful for the estimation of an average $\mathrm{N}_{2} \mathrm{O}$ production to be expected during any polar winter. Calculations of the $\mathrm{N}_{2} \mathrm{O}$ production rates have been performed for different scenarios of polar winter $\mathrm{NO}_{\mathrm{x}}$ descent. In the nominal scenario, $\mathrm{NO}_{\mathrm{x}}$ abundances are $20 \mathrm{ppbv}$ at $50 \mathrm{~km}$ and increase to $800 \mathrm{ppbv}$ at $75 \mathrm{~km}$ $(10 \mathrm{ppmv}$ at $100 \mathrm{~km})$. The "high $\mathrm{NO}_{\mathrm{x}}$ " scenario reflects the $\mathrm{NO}_{\mathrm{x}}$ abundances observed in February 2004 when the unusual descent of upper atmospheric air occurred in the $\mathrm{NH}$ polar vortex. In agreement with observations of ACE-FTS (Rinsland et al., 2006) and MIPAS (Funke et al., 2007), we have assumed in this scenario $100 \mathrm{ppbv}$ at $50 \mathrm{~km}$, increasing to 4 ppmv at $75 \mathrm{~km}(20 \mathrm{ppmv}$ at $100 \mathrm{~km})$. The $\mathrm{NO}_{\mathrm{x}}$ partitioning was taken from Whole Atmosphere Community Climate Model (WACCM) calculations (Garcia et al., 2007) for January, $90^{\circ} \mathrm{N}$ (polar night) and $60^{\circ} \mathrm{N}$ at noon (i.e., $80^{\circ} \mathrm{SZA}$ ). In these simulations, the polar night $\mathrm{NO}_{\mathrm{x}}$ partitioning in the mesosphere shows only small inter- and intra-annual variations. Nominal temperatures were taken from the Mass Spectrometer and Incoherent Scatter Radar empirical model (NRLMSISE-00) (Picone et al., 2002) for January, $90^{\circ} \mathrm{N}$. We also included an additional temperature scenario for "strong descent" conditions which reflects the thermal structure over the North pole during end of January 2004, when temper-

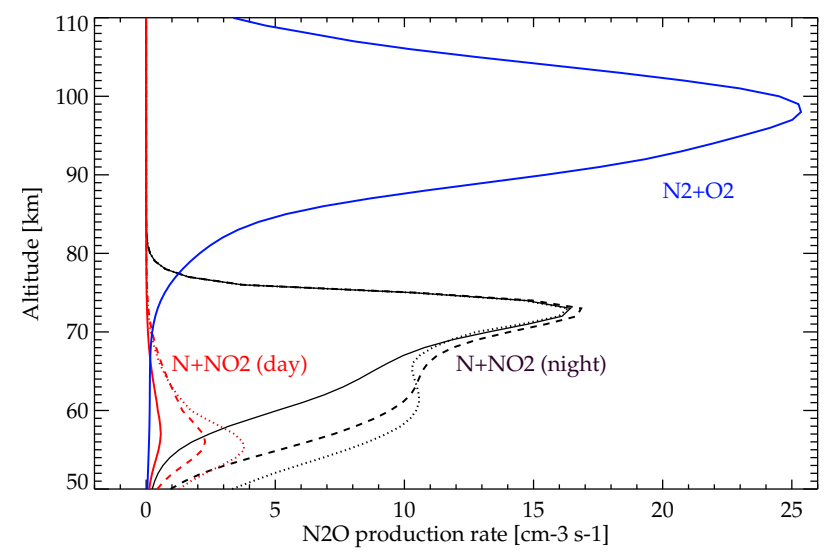

Fig. 10. Estimated EEP-related $\mathrm{N}_{2} \mathrm{O}$ productions by Reaction (R1) at polar night (solid black line) and day $\left(\mathrm{SZA}=80^{\circ}\right)$ conditions (solid red line), as well as by Reaction (R2) (solid blue line) for the nominal scenario. Dashed and dotted lines represent $\mathrm{N}_{2} \mathrm{O}$ productions for the "high $\mathrm{NO}_{\mathrm{x}}$ " scenario combined with the nominal and the "strong descent" temperature scenarios, respectively (only Reaction R1). See text for further details.

atures $30 \mathrm{~K}$ higher ( $40 \mathrm{~K}$ lower) than MSIS were observed at $70 \mathrm{~km}(50 \mathrm{~km})$ by the Sounding of the Atmosphere using Broadband Emission Radiometry (SABER) instrument (Hauchecorne et al., 2007). Profiles of temperature and vmrs of $\mathrm{NO}$ and $\mathrm{NO}_{2}$ for the different scenarios are shown in Fig. 9. Atomic oxygen densities required for the calculation of $P_{2}$ have been taken from WACCM calculations for January, $90^{\circ} \mathrm{N}$. Rate constants for Reactions (R1-4) were taken from Sander et al. (2006), while the quenching rate $k_{5}$ of Reaction (R5) was taken from Zipf and Prasad (1980).

Figure 10 shows the estimated $\mathrm{N}_{2} \mathrm{O}$ production rates $P_{1}$ and $P_{2}$ due to Reactions (R1) and (R2) respectively, in the presence of EEP. Apart of the nominal scenario, $P_{1}$ is also shown for the "high $\mathrm{NO}_{\mathrm{x}}$ " scenario combined with the nominal and the "strong descent" temperature scenarios. Since $P_{1}$ depends on illumination, both, polar night and sun overhead conditions have been considered. $\mathrm{N}_{2} \mathrm{O}$ production due to Reaction (R2) is independent of temperature and the $\mathrm{NO}_{\mathrm{x}}$ abundance. Thus, we have considered the nominal scenario only for the estimation of $P_{2}$.

The peak nighttime production rate $P_{1}$ due to Reaction (R1), located around $73 \mathrm{~km}$, is on the order of $15 \mathrm{~cm}^{-3} \mathrm{~s}^{-1}$ (see Fig. 10). The daytime contribution of this reaction has its maximum around $55 \mathrm{~km}$ with a $\mathrm{N}_{2} \mathrm{O}$ production rate considerably smaller than the corresponding nighttime contribution. This is expected, since daytime $\mathrm{NO}_{2}$ abundances are very small due to $\mathrm{NO}_{2}$ photolysis. Daytime $\mathrm{N}$ concentrations are driven by NO photolysis rather than by electron impact, which induces a pronounced dependence of $P_{1}$ on the $\mathrm{NO}_{\mathrm{x}}$ availability during day (compare dashed and solid red line in Fig. 10). This dependence on $\mathrm{NO}_{\mathrm{x}}$ is, how- 
ever, negligible at the $P_{1}$ peak height, around $73 \mathrm{~km}$, during night. The reason is that for the atmospheric conditions there, atomic nitrogen losses are dominated by Reactions (R1) and (R3), both involving $\mathrm{NO}_{\mathrm{x}}$. In consequence, the $\mathrm{N}_{2} \mathrm{O}$ production is mainly driven by the ionization rate and the $\mathrm{NO} / \mathrm{NO}_{2}$ partitioning, there. The latter, however, is expected to introduce only a small variability of $P_{1}$. At altitudes below the peak height, the nighttime production rate $P_{1}$ depends more strongly on the $\mathrm{NO}_{\mathrm{x}} \mathrm{vmr}$, since atomic nitrogen losses due to Reaction (R4) are getting more important towards lower altitudes. An $800 \%$ increase of $\mathrm{NO}_{\mathrm{x}}$ in the "high $\mathrm{NO}_{\mathrm{x}}$ " scenario compared to the nominal scenario results in a $50 \%$ increase in the $\mathrm{N}_{2} \mathrm{O}$ production at $60 \mathrm{~km}$.

Temperature also affects the $\mathrm{N}_{2} \mathrm{O}$ production by Reaction (R1). This is related to the strong temperature dependence of the atomic nitrogen losses by Reaction (R4), leading to a loss at temperatures around $255 \mathrm{~K}$ faster by one order of magnitude compared to temperatures around $220 \mathrm{~K}$. When considering the "strong descent" temperature scenario, reflecting the conditions during the Arctic mid-winter 2004, the $P_{1}$ profiles are significantly increased below $63 \mathrm{~km}$ and slightly decreased above, compared to the nominal temperature scenario (compare dotted and dashed lines in Fig. 10).

For the interpretation of the observed $\mathrm{N}_{2} \mathrm{O}$ enhancements in terms of possible production by Reaction (R1), it is necessary to assess the dependence of $P_{1}$ during night on both temperature and $\mathrm{NO}_{\mathrm{x}}$ availability in more detail. Therefore, we have performed calculations of $P_{1}$ for various temperatures between 220 and $270 \mathrm{~K}$ and NO $x$ vmrs up to 4 ppmv (not shown). It turned out that for typical polar winter temperatures of $220 \mathrm{~K}$ at $70 \mathrm{~km}, P_{1}$ is rather proportional to $\mathrm{NO}_{\mathrm{x}}$ up to approximately $20 \mathrm{ppbv}$, while for $\mathrm{NO}_{\mathrm{x}}$ abundances larger than $100 \mathrm{ppbv}$ the impact of the NOx abundance on $P_{1}$ is weak. $\mathrm{NO}_{\mathrm{x}}$ abundances of more than $100 \mathrm{ppbv}$ are generally found above $70 \mathrm{~km}$ during typical polar winters. For perturbed temperatures of $255 \mathrm{~K}$, the linear dependence on $\mathrm{NO}_{\mathrm{x}}$ is extended up to $150 \mathrm{ppbv}$. The region of weak $\mathrm{NO}_{\mathrm{x}}$ dependence starts at $\mathrm{NO}_{\mathrm{x}}$ vmrs around 500 ppbv. Since such high temperatures are generally found in winters with strong subsidence and hence high $\mathrm{NO}_{\mathrm{x}}$ availability, $P_{1}$ is expected to be rather independent on $\mathrm{NO}_{\mathrm{x}}$ at its peak height also in presence of high temperatures.

The maximum of the production rate $P_{2}$ is located at 95$100 \mathrm{~km}$ with a magnitude of $25 \mathrm{~cm}^{-3} \mathrm{~s}^{-1}$ and decreasing to values smaller than $1 \mathrm{~cm}^{-3} \mathrm{~s}^{-1}$ below $75 \mathrm{~km} . P_{2}$ is mainly driven by the EEP ionization rate, though above $90 \mathrm{~km}$, increasing atomic oxygen densities make $P_{2}$ dependent on the $\mathrm{O} / \mathrm{O}_{2}$ partitioning. At the $P_{2}$ peak height, around half of the EEP-generated $\mathrm{N}_{2}\left(\mathrm{~A}^{3} \Sigma_{u}^{+}\right)$molecules are quenched by atomic oxygen before they can react with $\mathrm{O}_{2}$ to form $\mathrm{N}_{2} \mathrm{O}$.

Despite this dependence on the $\mathrm{O} / \mathrm{O}_{2}$ partitioning, $\mathrm{N}_{2} \mathrm{O}$ production by Reaction (R2) shows similarities with the EEP-induced NO production in terms of both source region and variability. The magnitude of the NO production, however, is higher than our estimates of the $\mathrm{N}_{2} \mathrm{O}$ production by
Reaction (R2) by approximately a factor of 200, assuming that $0.7 \mathrm{NO}$ molecules are produced by each ion pair (Jackman et al., 2005). In consequence, we would expect that during polar winter, when photochemical losses are small, the $\mathrm{N}_{2} \mathrm{O}$ produced by Reaction (R2) is about $0.5 \%$ of the $\mathrm{NO}_{\mathrm{x}}$ abundance in air masses descended from the upper atmosphere.

During mid winter, the average polar $\mathrm{NO}_{2}$ abundances at $58 \mathrm{~km}$, as shown in Figs. 7 and 8, represent a good proxy of total $\mathrm{NO}_{\mathrm{x}}$. During the 2002 Antarctic and 2002/2003 Arctic winters, observed $\mathrm{NO}_{2}$ abundances at $58 \mathrm{~km}$ were generally lower than $15 \mathrm{ppbv}$. Hence, a negligible contribution by Reaction (R2) to the observed $\mathrm{N}_{2} \mathrm{O}$ enhancements of less than $0.07 \mathrm{ppbv}$ would be expected at this altitude. However, during the Antarctic winter 2003, when $\mathrm{NO}_{2}$ abundances of more than $100 \mathrm{ppbv}$ were measured, this contribution could have made up to $0.5 \mathrm{ppbv}$, which is about $40 \%$ of the $\mathrm{N}_{2} \mathrm{O}$ enhancements observed in this period. During January-March 2004 in the Arctic, the contribution due to Reaction (R2) could have even been as high as $1.5 \mathrm{ppbv}$ which makes up $25 \%$ of the observed $\mathrm{N}_{2} \mathrm{O}$ enhancements. We recall, however, that these estimates represent an upper limit for a possible contribution of Reaction (R2).

In the lower thermosphere, $\mathrm{N}_{2} \mathrm{O}$ abundances on the order of several $100 \mathrm{ppbv}$ would then be expected due to Reaction (R2). Unfortunately, there are no thermospheric $\mathrm{N}_{2} \mathrm{O}$ measurements available which would support such high $\mathrm{N}_{2} \mathrm{O}$ amounts. We thus have looked at MIPAS spectra taken in the upper atmospheric observation mode on 11 June 2003, which includes tangent heights up to $170 \mathrm{~km}$. No evidence for $\mathrm{N}_{2} \mathrm{O}$ emissions at tangent heights above $90 \mathrm{~km}$ was found in any of the $\mathrm{N}_{2} \mathrm{O}$ bands included in the MIPAS spectra. However, due to the low signal-to-noise ratio at these altitudes, only $\mathrm{N}_{2} \mathrm{O}$ abundances higher than approximately $200 \mathrm{ppbv}$ could have been detected by MIPAS at these tangent heights.

In this sense, a possible contribution of Reaction (R2) can neither be proven nor excluded. In any case, even when assuming a maximum efficiency of this reaction to form $\mathrm{N}_{2} \mathrm{O}$, its contribution could only explain a small fraction of the observed $\mathrm{N}_{2} \mathrm{O}$ enhancements.

Assuming a continuous EEP-induced $\mathrm{N}_{2} \mathrm{O}$ production with typical rates as provided by our estimates of $P_{1}$ and a transport-limited $\mathrm{N}_{2} \mathrm{O}$ lifetime of a few weeks, Reaction (R1) would lead to $\mathrm{N}_{2} \mathrm{O}$ abundances on the order of several ppbv at its source region around $70 \mathrm{~km}$. Since our estimations reflect conditions of average geomagnetic activity, even higher mesospheric $\mathrm{N}_{2} \mathrm{O}$ abundances would be found in periods of elevated geomagnetic activity, e.g. during the Antarctic winter 2003 and Arctic winter 2004. Although $\mathrm{N}_{2} \mathrm{O}$ abundances are expected to decrease towards lower altitudes due to dilution during the descent, it seems plausible that $\mathrm{N}_{2} \mathrm{O}$ abundances such as observed at $58 \mathrm{~km}$ during the 2002-2004 polar winters could have been caused by Reaction (R1). It has already been demonstrated by CMAM model calculations (Semeniuk et al., 2008), that a dominant contribution to 
the mesospheric $\mathrm{N}_{2} \mathrm{O}$ enhancements during the Arctic winter 2004 was generated by this reaction during night. It is thus very likely, that its nighttime contribution was also responsible for the major part of the $\mathrm{N}_{2} \mathrm{O}$ enhancements observed in the other polar winters. Its daytime contribution, which does not require the presence of EEP, is expected to be considerably smaller. Nevertheless, minor $\mathrm{N}_{2} \mathrm{O}$ amounts could have been produced in illuminated regions at altitudes below $60 \mathrm{~km}$, in particular during winters with high $\mathrm{NO}_{\mathrm{x}}$ availability (i.e., February 2004). A dominant nighttime contribution originated from a source region around $70-75 \mathrm{~km}$ is also supported by the finding that the observed $\mathrm{N}_{2} \mathrm{O}$ enhancements at $58 \mathrm{~km}$ are more efficiently modulated by dynamical factors than by the electron flux variability.

As demonstrated above, nighttime $\mathrm{N}_{2} \mathrm{O}$ production by Reaction (R1) is mainly driven by the EEP-induced ionization rate around $73 \mathrm{~km}$. Hence, except for dynamical modulations, the inter-annual variations of the observed polar winter $\mathrm{N}_{2} \mathrm{O}$ enhancements should be correlated to the flux variations of precipitating electrons with energies greater than $100 \mathrm{keV}$. Indeed, we found the highest $\mathrm{N}_{2} \mathrm{O}$ amounts in the $2003 \mathrm{SH}$ and $2004 \mathrm{NH}$ winters with most elevated fluxes of $>100 \mathrm{keV}$ electrons. However, it is striking that the $\mathrm{N}_{2} \mathrm{O}$ enhancements observed during the $2003 \mathrm{SH}$ winter at $58 \mathrm{~km}$ were about 5 times smaller than those of the $2004 \mathrm{NH}$ winter, although the observed $>100 \mathrm{keV}$ electron fluxes were comparable. This apparent asymmetry could be explained by the unusually strong polar vortex during the $2004 \mathrm{NH}$ winter leading to a more efficient descent of $\mathrm{N}_{2} \mathrm{O}$ produced around $73 \mathrm{~km}$ than in the $2003 \mathrm{SH}$ winter. Further, favored by the low temperatures and high $\mathrm{NO}_{\mathrm{x}}$ availability, significant $\mathrm{N}_{2} \mathrm{O}$ production could have occurred at altitudes below $65 \mathrm{~km}$ during the 2004 $\mathrm{NH}$ winter.

We have further observed that the $\mathrm{N}_{2} \mathrm{O} / \mathrm{NO}_{2}$ ratio tended to be considerably higher at the beginning and the end of the polar winters. As discussed above, the non-linear dependence of the nighttime fraction of $P_{1}$ on the $\mathrm{NO}_{\mathrm{x}}$ availability could be responsible for variations of the $\mathrm{N}_{2} \mathrm{O} / \mathrm{NO}_{2}$ ratio: At the beginning and the end of the winter, when only small amounts of $\mathrm{NO}_{\mathrm{x}}$ are available, $\mathrm{N}_{2} \mathrm{O}$ increases linearly with $\mathrm{NO}_{2}$, while during mid winter, sufficient $\mathrm{NO}_{\mathrm{x}}$ is available to make the $\mathrm{N}_{2} \mathrm{O}$ production dependent on the EEP-induced ionization and the $\mathrm{NO}_{\mathrm{x}}$ partitioning, only.

In summary, we have shown that the magnitude and temporal evolution of the observed $\mathrm{N}_{2} \mathrm{O}$ enhancements during the 2002-2004 polar winters are in concordance with a dominant nighttime $\mathrm{N}_{2} \mathrm{O}$ source around $73 \mathrm{~km}$ due to Reaction (R1) which is driven by energetic electron precipitation. The variability of $\mathrm{N}_{2} \mathrm{O}$ at $58 \mathrm{~km}$ over various winters seems to be driven by both dynamical conditions and variations of the source strength. Further, we cannot exclude that Reaction (R2) contributed additionally by up to $25-40 \%$ to the observed enhancements.

\section{Conclusions}

We have presented observations of enhanced $\mathrm{N}_{2} \mathrm{O}$ abundances, ranging from 0.5 to $6 \mathrm{ppbv}$ in the polar upper stratosphere/lower mesosphere, which have been taken by the MIPAS instrument on the Envisat satellite during the Arctic and Antarctic winters in the period July 2002-March 2004. These $\mathrm{N}_{2} \mathrm{O}$ enhancements have been found in two data sets resulting from independent processing, the first, generated at IMK/IAA, and the second, generated by the operational data processing performed by ESA. The good agreement of both data sets makes is unlikely that the observed $\mathrm{N}_{2} \mathrm{O}$ enhancements are related to retrieval artifacts.

Simultaneous $\mathrm{N}_{2} \mathrm{O}$ and $\mathrm{CH}_{4}$ observations show a pronounced anti-correlation during polar winters at $\mathrm{CH}_{4}$ levels lower than $0.1 \mathrm{ppmv}$. This behavior gives clear evidence that the $\mathrm{N}_{2} \mathrm{O}$ enhancements are of chemical rather than dynamical origin. As a consequence, polar winter $\mathrm{N}_{2} \mathrm{O}-\mathrm{CH}_{4}$ correlations should be used with caution in tracer-tracer studies due to the perturbations by this mesospheric $\mathrm{N}_{2} \mathrm{O}$ source.

The finding that chemical production of $\mathrm{N}_{2} \mathrm{O}$ occurred in the mesosphere during all polar winters in the period 20022004 , though with variable magnitude, makes it rather unlikely that mesospheric $\mathrm{N}_{2} \mathrm{O}$ enhancements are infrequent isolated phenomena.

The polar winter $\mathrm{N}_{2} \mathrm{O}$ enhancements observed at $58 \mathrm{~km}$ occurred in the presence of $\mathrm{NO}_{\mathrm{x}}$ intrusions from the upper atmosphere which were related to energetic particle precipitation. Further, the inter-annual variations of polar winter averages of mesospheric $\mathrm{N}_{2} \mathrm{O}$ correlate well with those of precipitating electrons fluxes as measured by the MEPED instrument, which hints at an EEP-related $\mathrm{N}_{2} \mathrm{O}$ source. On the other hand, we found a pronounced anti-correlation of the temporal evolutions of $\mathrm{N}_{2} \mathrm{O}$ and $\mathrm{CH}_{4}$ at $58 \mathrm{~km}$, which hints at a dynamical modulation of descending $\mathrm{N}_{2} \mathrm{O}$ from a source region at higher altitudes.

The analysis of possible chemical production mechanisms shows that the major part of the observed $\mathrm{N}_{2} \mathrm{O}$ enhancements is most likely generated under dark conditions by the reaction of $\mathrm{NO}_{2}$ with atomic nitrogen in the presence of energetic particle precipitation. $\mathrm{N}_{2} \mathrm{O}$ production due to this mechanism has its maximum around $73 \mathrm{~km}$. The polar winter $\mathrm{N}_{2} \mathrm{O}$ abundances observed at $58 \mathrm{~km}$ seem to be modulated by both variations of the source strength and dynamical factors driving the efficiency of the descent from the source region. An additional source of $\mathrm{N}_{2} \mathrm{O}$ in the middle and upper polar atmosphere could represent the reaction of $\mathrm{N}_{2}\left(\mathrm{~A}^{3} \Sigma_{u}^{+}\right)$, generated by precipitating electrons, with $\mathrm{O}_{2}$, which would lead to $\mathrm{N}_{2} \mathrm{O}$ production peaking at altitudes around $90-100 \mathrm{~km}$. $\mathrm{N}_{2} \mathrm{O}$ produced by the latter mechanism could have then descended to the upper stratosphere and mesosphere during the 2002-2004 polar winters, where it could have contributed to the observed $\mathrm{N}_{2} \mathrm{O}$ enhancements by up to $25-40 \%$.

EEP-generated mesospheric $\mathrm{N}_{2} \mathrm{O}$ represents a continuous, though variable, source of stratospheric odd nitrogen during 
polar winters. This source, however, is of minor importance when compared to EEP-induced NO production.

The total fraction of stratospheric $\mathrm{N}_{2} \mathrm{O}$ produced in the upper atmosphere is difficult to assess directly from MIPAS observations since the EEP-generated $\mathrm{N} 2 \mathrm{O}$ which has descended into the middle or lower stratosphere during the winter can hardly be separated from the much higher background $\mathrm{N}_{2} \mathrm{O}$ abundances. However, it can be estimated indirectly from the deposition of EEP-generated $\mathrm{NO}_{\mathrm{y}}$ into the stratosphere (Funke et al., 2005), assuming a constant ratio of $\mathrm{N}_{2} \mathrm{O}$ and $\mathrm{NO}_{\mathrm{y}}$ of upper atmospheric origin below $50 \mathrm{~km}$. This is justified since at these altitudes none of $\mathrm{N}_{2} \mathrm{O}$ and $\mathrm{NO}_{\mathrm{y}}$ is produced in situ and none of them show significant photochemical losses during polar winter. The estimated fraction of EEP-generated $\mathrm{N}_{2} \mathrm{O}$ to the total stratospheric $\mathrm{N}_{2} \mathrm{O}$ inside the polar vortex above $20 \mathrm{~km}(30 \mathrm{~km})$ never exceed $1 \%(10 \%)$ during the 2002-2004 winters. Compared to the global amount of stratospheric $\mathrm{N}_{2} \mathrm{O}$, the EEP-generated contribution is negligible.

Acknowledgements. The IAA team was supported by the Spanish project ESP2004-01556 and EC FEDER funds. The IMK team was supported by the Priority Program CAWSES of the German science foundation (DFG) under the project MANOXUVA. The authors acknowledge ESA for providing MIPAS spectra and level-2 data, as well as ECMWF for meteorological analysis data.

Edited by: W. Lahoz

\section{References}

Baker, D. N., Kanekal, S. G., Li, X., Monk, S. P., Goldstein, J., and Burch, J. L.: An extreme distortion of the Van Allen belt arising from the 'Halloween' solar storm 2003, Nature, 432, 878-881, doi:10.1038/nature03116, 2004.

Callis, L. B., Natarajan, M., Lambeth, J. D., and Baker, D. N.: Solar atmospheric coupling by electron (SOLACE 2 . Calculated stratospheric effects of precipitationg electron, 1979-1988, J. Geophys. Res., 103, 28 421-28 438, 1998.

de Sousa, A. R., Touzeau, M., and Petitdidier, M.: Quenching reactions of metastable $\mathrm{N}_{2}\left(\mathrm{~A}^{3} \Sigma, v=0,1,2\right)$ molecule with $\mathrm{O}_{2}$, Chem. Phys. Lett., 121, 423-428, 1985.

Echle, G., von Clarmann, T., Dudhia, A., Flaud, J.-M., Funke, B., Glatthor, N., Kerridge, B., López-Puertas, M., Martín-Torres, F. J., and Stiller, G. P.: Optimized spectral microwindows for data analysis of the Michelson Interferometer for Passive Atmospheric Sounding on the Environmental Satellite, Appl. Optics., 39, 5531-5540, 2000.

European Space Agency: Envisat, MIPAS An instrument for atmospheric chemistry and climate research, ESA Publications Division, ESTEC, P. O. Box 299, 2200 AG Noordwijk, The Netherlands, SP-1229, 2000.

Evans, D. and Greer, M.: Polar Orbiting Environmental Satellite Space Environment Monitor - 2: Instrument Descriptions and Archive Data Documentation, NOAA Technical Memorandum OAR SEC-93, Oceanic and Atmospheric Research Laboratories, Space Environment Center, Boulder, Colorado, 2000.
Fischer, H. and Oelhaf, H.: Remote sensing of vertical profiles of atmospheric trace constituents with MIPAS limb-emission spectrometers, Appl. Optics., 35, 2787-2796, 1996.

Fischer, H., Birk, M., Blom, C., Carli, B., Carlotti, M., von Clarmann, T., Delbouille, L., Dudhia, A., Ehhalt, D., Endemann, M., Flaud, J. M., Gessner, R., Kleinert, A., Koopman, R., Langen, J., López-Puertas, M., Mosner, P., Nett, H., Oelhaf, H., Perron, G., Remedios, J., Ridolfi, M., Stiller, G., and Zander, R.: MIPAS: an instrument for atmospheric and climate research, Atmos. Chem. Phys., 8, 2151-2188, 2008,

http://www.atmos-chem-phys.net/8/2151/2008/.

Funke, B., López-Puertas, M., Gil-López, S., von Clarmann, T., Stiller, G. P., Fischer, H., and Kellmann, S.: Downward transport of upper atmospheric $\mathrm{NO}_{\mathrm{x}}$ into the polar stratosphere and lower mesosphere during the Antarctic 2003 and Arctic 2002/2003 winters, J. Geophys. Res., 110, D24308, doi:10.1029/ 2005JD006463, 2005.

Funke, B., López-Puertas, M., Fischer, H., Stiller, G. P., von Clarmann, T., Wetzel, G., Carli, B., and Belotti, C.: Comment on 'Origin of the January-April 2004 increase in stratospheric $\mathrm{NO}_{2}$ observed in northern polar latitudes' by J.-B. Renard et al., Geophys. Res. Lett., 34, L07813, doi:10.1029/2006GL027518, 2007.

Funke, B., García-Comas, M., López-Puertas, M., Glatthor, N., Stiller, G. P., von Clarmann, T., Semeniuk, K., and McConnell, J. C.: Enhancement of $\mathrm{N}_{2} \mathrm{O}$ during the October-November 2003 solar proton events, Atmos. Chem. Phys., 8, 3805-3815, 2008, http://www.atmos-chem-phys.net/8/3805/2008/.

Garcia, R. R., Marsh, D. R., Kinnison, D. E., Boville, B. A., and Sassi, F.: Simulation of secular trends in the middle atmosphere, J. Geophys. Res., 112, D09301, doi:10.1029/2006JD007485, 2007.

Glatthor, N., von Clarmann, T., Fischer, H., Funke, B., Grabowski, U., Höpfner, M., Kellmann, S., Kiefer, M., Linden, A., Milz, M., Steck, T., Stiller, G. P., Mengistu Tsidu, G., and Wang, D. Y.: Mixing processes during the Antarctic vortex split in September/October 2002 as inferred from source gas and ozone distributions from ENVISAT-MIPAS, J. Atmos. Sci., 62, 787-800, 2005.

Hauchecorne, A., Bertaux, J.-L., Dalaudier, F., Russell III, J. M., Mlynczak, M. G., Kyrölä, E., and Fussen, D.: Large increase of $\mathrm{NO}_{2}$ in the north polar mesosphere in January-February 2004: Evidence of a dynamical origin from GOMOS/ENVISAT and SABER/TIMED data, Geophys. Res. Lett., 34, L03810, doi:10. 1029/2006GL027628, 2007.

Iannuzzi, M. P., Jeffries, J. B., and Kaufman, F.: Product channels of the $\mathrm{N}_{2}\left(\mathrm{~A}^{3} \Sigma_{u}^{+}\right)+\mathrm{O}_{2}$ interaction, Chem. Phys. Lett., 87, 570574, 1982.

Jackman, C. H., DeLand, M. T., Labow, G. J., Fleming, E. L., Weisenstein, D. K., Ko, M. K. W., Sinnhuber, M., and Russell, J. M.: Neutral atmospheric influences of the solar proton events in October-November 2003, J. Geophys. Res., 110, A09S27, doi: 10.1029/2004JA01088, 2005.

Jackman, C. H., Marsh, D. R., Vitt, F. M., Garcia, R. R., Fleming, E. L., Labow, G. J., Randall, C. E., López-Puertas, M., Funke, B., von Clarmann, T., and Stiller, G. P.: Short- and medium-term atmospheric constituent effects of very large solar proton events, Atmos. Chem. Phys., 8, 765-785, 2008, http://www.atmos-chem-phys.net/8/765/2008/.

Manney, G. L., Krüger, K., Sabutis, J. L., Sena, S. A., and Pawson, 
S.: The remarkable 2003-2004 winter and other recent warm winters in the Arctic stratosphere since the late 1990s, J. Geophys. Res., 110, D04107, doi:10.1029/2004JD005367, 2005.

Michelsen, H. A., Manney, G. L., Gunson, M. R., Rinsland, C. P., and Zander, R.: Correlations of stratospheric abundances of $\mathrm{CH}_{4}$ and $\mathrm{N}_{2} \mathrm{O}$ derived from ATMOS measuremets, Geophys. Res. Lett., 25, 2777-2780, 1998a.

Michelsen, H. A., Manney, G. L., Gunson, M. R., and Zander, R.: Correlations of stratospheric abundances of $\mathrm{NO}_{\mathrm{y}}, \mathrm{O}_{3}, \mathrm{~N}_{2} \mathrm{O}$, and $\mathrm{CH}_{4}$ derived from ATMOS measurements, J. Geophys. Res., 103, 28 347-28 359, 1998b.

Nash, E. R., Newmann, P. A., Rosenfield, J. E., and Schoeberl, M. R.: An objective determination of the polar vortex using Ertel's potential vorticity, J. Geophys. Res., 101, 9471-9478, 1996.

Nett, H., Carli, B., Carlotti, M., Dudhia, A., Fischer, H., Flaud, J.M., Perron, G., Raspollini, P., and Ridolfi, M.: MIPAS Ground Processor and Data Products, in: Proc. IEEE 1999 International Geoscience and Remote Sensing Symposium, 28 June-2 July 1999, Hamburg, Germany, 1692-1696, 1999.

Nett, H., Perron, G., Sanchez, M., Burgess, A., and Mosner, P.: MIPAS in-flight calibration and processor verification, in: ENVISAT Calibration Review - Proc. of the European Workshop, 9-13 September 2002, ESTEC, Noordwijk, The Netherlands, CD-ROM, edited by: Sawaya-Lacoste, H., Vol. SP-520, ESA Publications Division, ESTEC, Postbus 299, 2200 AG Noordwijk, The Netherlands, 2002.

Newman, P. A. and Nash, E. R.: The Unusual Southern Hemisphere Stratosphere Winter of 2002, J. Atmos. Sci., 62, 614-628, 2005.

Picone, J., Hedin, A., Drob, D., and Aikin, A.: NRLMSISE00 empirical model of the atmosphere: Statistical comparisons and scientific issues, J. Geophys. Res., 107, 1468, doi:10.1029/2002JA009430, 2002.

Plumb, R. A., Waugh, D. W., and Chipperfield, M. P.: The effects of mixing on tracer relationships in the polar vortices, J. Geophys. Res., 105, $10047-10062,2000$.

Randall, C. E., Harvey, V. L., Singleton, C. S., Bailey, S. M., Bernath, P. F., Codrescu, M., Nakajima, H., and Russell III, J. M.: Energetic particle precipitation effects on the Southern Hemisphere stratosphere in 1992-2005, J. Geophys. Res., 112, D08308, doi:10.1029/2006JD007696, 2007.

Raspollini, P., Belotti, C., Burgess, A., Carli, B., Carlotti, M., Ceccherini, S., Dinelli, B. M., Dudhia, A., Flaud, J.-M., Funke, B., Höpfner, M., López-Puertas, M., Payne, V., Piccolo, C., Remedios, J. J., Ridolfi, M., and Spang, R.: MIPAS level 2 operational analysis, Atmos. Chem. Phys., 6, 5605-5630, 2006, http://www.atmos-chem-phys.net/6/5605/2006/.

Ray, E. A., Moore, F. L., Elkins, J. W., Hurst, D. F., Romashkin, P. A., Dutton, G., and Fahey, D. W.: Descent and mixing in the 1999-2000 northern polar vortex inferred from in situ tracer measurements, J. Geophys. Res., 107, 8285, doi:10.1029/ 2001JD000961, 2002.
Rinsland, C. P., Goldman, A., Elkins, J. W., Chiou, L. S., Hannigan, J. W., Wood, S. W., Mahieu, E., and Zander, R.: Long-term trend of $\mathrm{CH}_{4}$ at northern mid-latitudes: Comparison between ground-based infrared solar and surface sampling measurements, J. Quant. Spectrosc. Ra., 97, 457-466, doi:10.1016/j.jqsrt.2005. 07.002, 2006.

Sander, S. P., Friedl, R. R., Ravishankara, A. R., Golden, D. M., Kolb, C. E., Kurylo, M. J., Molina, M. J., Moortgat, G. K., Keller-Rudek, H., Finlayson-Pitts, B. J., Wine, P., Huie, R. E., and Orkin, V. L.: Chemical kinetics and Photochemical Data for the Use in Atmospheric Studies. Evaluation Number 15, JPL publication 06-2, Jet Propulsion Laboratory, 2006.

Semeniuk, K., McConnell, J. C., Jin, J. J., Jarosz, J. R., Boone, C. D., and Bernath, P. F.: $\mathrm{N}_{2} \mathrm{O}$ production by high energy auroral electron precipitation, J. Geophys. Res., 113, D16302, doi:10. 1029/2007JD009690, 2008.

Siskind, D. E.: Atmospheric science across the Stratopause, Vol. 123, Geophysical Monograph, Chap. On the coupling between middle and upper atmospheric odd nitrogen, American Geophysical Union, 101-116, 2000.

Stiller, G. P., von Clarmann, T., Funke, B., Glatthor, N., Hase, F., Höpfner, M., and Linden, A.: Sensitivity of trace gas abundances retrievals from infrared limb emission spectra to simplifying approximations in radiative transfer modelling, J. Quant. Spectrosc. Ra., 72, 249-280, 2002.

von Clarmann, T., Chidiezie Chineke, T., Fischer, H., Funke, B., García-Comas, M., Gil-López, S., Glatthor, N., Grabowski, U., Höpfner, M., Kellmann, S., Kiefer, M., Linden, A., LópezPuertas, M., López-Valverde, M. Á., Mengistu Tsidu, G., Milz, M., Steck, T., and Stiller, G. P.: Remote Sensing of the Middle Atmosphere with MIPAS, in: Remote Sensing of Clouds and the Atmosphere VII, edited by: Schäfer, K., Lado-Bordowsky, O., Comerón, A., and Picard, R. H., Vol. 4882, SPIE, Bellingham, WA, USA, 172-183, 2003a.

von Clarmann, T., Glatthor, N., Grabowski, U., Höpfner, M., Kellmann, S., Kiefer, M., Linden, A., Mengistu Tsidu, G., Milz, M., Steck, T., Stiller, G. P., Wang, D. Y., Fischer, H., Funke, B., Gil-López, S., and López-Puertas, M.: Retrieval of temperature and tangent altitude pointing from limb emission spectra recorded from space by the Michelson Interferometer for Passive Atmospheric Sounding (MIPAS), J. Geophys. Res., 108, 4736, doi:10.1029/2003JD003602, 2003b.

Zipf, E. C.: A laboratory study on the form of nitrous oxide by the reaction $\mathrm{N}_{2}\left(\mathrm{~A}^{3} \Sigma_{u}^{+}\right)+\mathrm{O}_{2} \rightarrow \mathrm{N}_{2} \mathrm{O}+\mathrm{O}$, Nature, 287, 523-524, 1980.

Zipf, E. C. and Prasad, S.: Production of nitrous oxide in the auroral D and E regions, Nature, 287, 525-526, 1980. 